\title{
Candidiasis, Bacterial Vaginosis, Trichomoniasis and Other Vaginal Conditions Affecting the Vulva
}

\author{
Pedro Vieira-Baptista and Jacob Bornstein
}

\subsection{Introduction}

The term "vulvovaginitis" encompasses a broad and heterogeneous number of conditions, which, contrarily to what the suffix "-itis" implies, are not necessarily infectious (e.g. cytolytic vaginosis $[\mathrm{CyV}]$ ) or inflammatory (e.g. bacterial vaginosis [BV]).

The clinical or symptomatic approach to the management of vulvovaginitis is very limited; a significant number of women will not fit the "traditional" diagnosis of candidiasis, BV, or trichomoniasis. A proper approach, encompassing other neglected diagnoses, will reduce the number of women without a diagnosis (reported to be as high as $30 \%$ ), and lead to more adequate treatments.

These entities, despite not life-threatening, can seriously contribute to impair the quality of life of affected women at all levels, and leave deep and long lasting psychosexual sequelae.

\section{Candidiasis: Breaking the Myths}

- A significant number of women will not fit the "traditional" diagnosis of candidiasis, BV, or trichomoniasis

- Candida albicans infection does not consist only of vaginal discharge. In fact, its mycelium can penetrate the vaginal mucosa, up to 10 layers of cells deep.

- Despite the long list of risk factors and associations with vulvovaginal candidiasis (VVC), most of the times a precipitating factor cannot be identified.

- Itch is the most notorious symptom of VVC-but most women with itching do not have a VVC.

- Identification of Candida in cultures, per se, cannot be assumed as a diagnosis of VVC, as it does not distinguish colonization from infection.

\subsection{Vulvovaginal Candidiasis (or Candidosis)}

P. Vieira-Baptista $(\triangle)$

Lower Genital Tract Unit, Gynaecolgy and Obstetrics

Department, Centro Hospitalar de São João, Porto,

Portugal

J. Bornstein

Department of Obstetrics and Gynecology Galilee

Medical Center, Bar-Ilan University Faculty

of Medicine, Nahariya, Israel

It is debatable whether the symptomatic presence of fungi from the genera Candida in the vagina should be referred to as vulvovaginal "candidiasis" or "candidosis" (VVC), since inflammation is not always present, and "-osis" is the suffix usually used for fungal infections. 


\subsubsection{Aetiology and Pathophysiology}

Approximately $90 \%$ of the cases of VVC are caused by $C$. albicans. The next most common agent is $C$. glabrata; much less frequently $(<1-$ $2 \%$ of the total), C. krusei, C. tropicalis, C. dubliniensis and $C$. parapsilosis, among others, can also be involved [1]. The non-albicans Candida (NAC) species are more commonly encountered in cases of recurrent VVC (in up to 20\%), and in diabetic or immunocompromised women.

Co-infection is uncommon ( $<10 \%$ of cases) and usually the involved species are $C$. albicans and C. glabrata [1].

Candida is commonly found in the form of blastospores in the mucous layer, as a commensal. Infection starts with adherence to vaginal epithelial cells, mediated by mannoproteins. For the species that form mycelium (C. albicans), it is a fundamental step in eliciting an immune response and in causing host cell damage. The mycelium, in a phenomenon mediated, among others, by candidalysin, penetrates the vaginal mucosa, up to 10 layers of cells deep [2].

The first line of defence, innate immunity, includes phagocytosis by neutrophils and macrophages, activation of the complement cascade, direct cellular killing, and promotion of opsonization via complement receptors. This process is mediated by the binding of mannose-binding lectin (MBL) to Candida and explains why women with mutations of the MBL gene, especially at the codon 54, are more prone to recurrent VVC [3].

Acquired immunity against Candida is mostly mediated by $\operatorname{IgA}$ secretion, as well as a Th2 type cytokine profile response. However, an impaired Th1 response has been associated with increased risk of recurrent VVC [4].

A normal lactobacillary flora is protective against VVC due to: (1) competition for nutrients, (2) competition for adhesion sites, (3) production of biosurfactants that decrease the adherence of Candida, (4) production of $\mathrm{H}_{2} \mathrm{O}_{2}$, (5) production of toxic peptides and fatty acids, (6) downregulation of genes responsible for the biofilm production, and (7) inhibition of filamentation [5]. Interestingly however, most

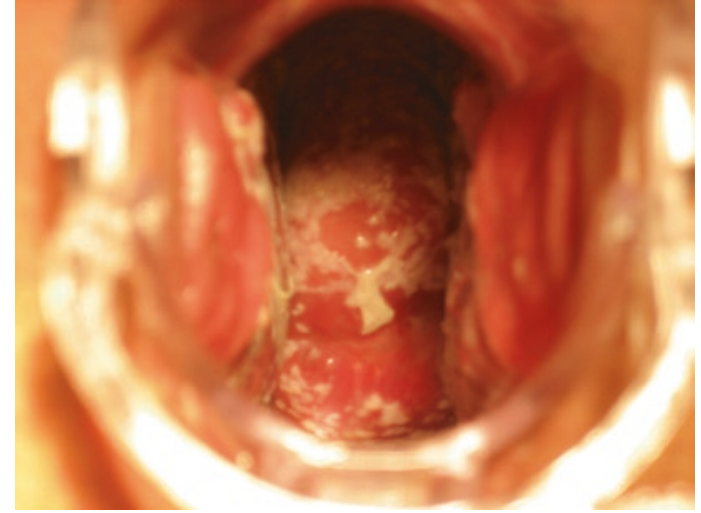

Fig. 24.1 Typical curdy white discharge of VVC (cultures were positive for $C$. krusei)

cases of VVC occur in women with normal flora [2] (Fig. 24.1).

\subsubsection{Prevalence and Epidemiology}

VVC is not a reportable disease, thus all prevalence data are based on studies performed in different settings, often not representative of the population, and looking for different outcomes [1].

It is considered the second most frequent cause of "vulvovaginitis" symptoms, after BV. Candida can be responsible for the symptoms of vulvovaginitis in up to $30 \%$ of cases [6]. However, the perception of its prevalence, from patients' and health care providers' point of view, is higher; most cases are treated with over-the-counter medication, without proper confirmation.

Vaginal Candida colonization is found in at least $10-20 \%$ of healthy, reproductive age, asymptomatic women [7]. It is higher in pregnant women $(20-40 \%)$, especially in the third trimester, due to the high levels of estrogens, and in immunocompromised women [8]. The cumulative incidence of colonization over 1 year is as high as $70 \%$ [9].

Up to $75 \%$ of women will experience at least one episode during their life time [1]. Half of these will suffer at least one additional episode and 5-10\% will have recurrent VVC (Table 24.1) $[1,6,10]$.

There is no data suggesting an increase in the incidence of VVC over the years [2]. 


\subsubsection{Classification}

The majority of episodes of VVC (90\%) are considered uncomplicated. When the episodes are recurrent, associated with severe symptoms, caused by NAC species, or occur in diabetic or immunocompromised patients, it is classified as complicated [10] (Table 24.1).

According to most societies' guidelines, recurrent VVC is defined as four or more symptomatic episodes in 1 year. Most do not refer the need for a laboratorial confirmation (wet mount, culture, Gram staining) of every episode. We support that confirmation is necessary, in order to exclude alternative diagnosis (cytolytic vaginosis, allergic vaginitis) or NAC species.

\subsubsection{Risk Factors and Associations}

Despite the long list of risk factors and associations with VVC (Table 24.2), most of the times a precipitating factor cannot be identified [11].

The presence of Candida is highly related to oestrogen levels, and, accordingly it is much

Table 24.1 Classification of VVC

\begin{tabular}{l|l}
\hline Uncomplicated & $\begin{array}{l}\text { All } 4 \text { criteria must be met: } \\
\text { - Sporadic or infrequent } \\
\text { - Mild-to-moderate symptoms } \\
\text { - Caused by Candida albicans } \\
\text { - Non immunocompromised } \\
\text { woman }\end{array}$ \\
\hline Complicated & $\begin{array}{l}\text { Any of these criteria present: } \\
\text { - Recurrent VVC } \\
\text { - Severe (extensive vulvar } \\
\text { erythema, oedema, excoriations } \\
\text { and fissures) } \\
\bullet \text { Non-albicans species involved } \\
\bullet \text { Women with diabetes, pregnancy, } \\
\text { immunocompromising } \\
\text { conditions (e.g. HIV infection), } \\
\text { debilitation, or } \\
\text { immunosuppressive therapy (e.g. } \\
\text { corticosteroids) } \\
\bullet \text { Four or more symptomatic } \\
\text { episodes within 1 year } \\
\bullet \text { Each episode must have } \\
\text { laboratorial confirmation } \\
\text { (not recommended by all } \\
\text { societies) }\end{array}$ \\
\hline Recurrent \\
\end{tabular}

less common in prepubertal and postmenopausal women, and, contrarily, more common in pregnant women.

The role of oestrogens is complex: (1) promotes Candida proliferation and virulence, (2) induces immunological tolerance, and (3) promotes the production of glycogen by the vaginal epithelium cells. Progesterone, on one side, promotes Candida proliferation, but on the other has been shown also to inhibit its ability of forming biofilms and mycelium $[12,13]$.

The role of oral contraceptives in VVC is controversial. Modern low dose pills seem to pose a low risk, if any. Progestin-only pills and subdermal progestin implants seem to be associated with a lower risk of colonization, probably due to the relative state of hypoestrogenism they induce [14].

Copper intrauterine devices (IUDs) and, more recently, also levonorgestrel-releasing intrauterine systems (LVG-IUS) were associated with an increased risk of colonization by Candida [14, 15]. The formation of biofilms in the IUDs/LVGIUS, to which Candida can adhere and act as a reservoir, is a possible explanation. However, this phenomenon does not seem to occur with the vaginal ring [16].

Glycogen, which is increased in cases of high levels of oestrogens, of steroids use, and in diabetic women, is the main growth substrate for Candida [12].

In women colonized with Candida, the use of antibiotics and the consequent destruction of the vaginal lactobacilli is a well-established risk factor [6] (Table 24.2).

Factors that can decrease the inflammatory response are associated with VVC. These can be genetic (MBL gene polymorphisms, diabetes) or acquired (HIV, drugs, low zinc levels).

Behavioural and environmental factors are the most complex ones to understand and with the most disparate results across studies. Higher temperatures and increased moisture, whether derived from the climate or local conditions (obesity, non-breathable clothes, etc.) seem to be related to increased rates of VVC. Some authors consider panty liners a risk factor for VVC, but systematic reviews do not support it [17]. 
Table 24.2 Risk factors associated with VVC

\begin{tabular}{|c|c|}
\hline Hormonal factors & Consequences/mechanisms of action \\
\hline $\begin{array}{l}\text { - Increased oestrogen levels (e.g. pregnancy) } \\
\text { - Menopausal hormonal replacement therapy } \\
\text { - Oral contraceptives (?) }\end{array}$ & $\begin{array}{l}\text { - } \uparrow \text { Adherence of Candida to vaginal cells } \\
\text { - } \uparrow \text { Mycelium formation } \\
\text { - } \downarrow \text { Vaginal immunological response } \\
\text { - } \uparrow \text { Levels of vaginal glycogen } \\
\text { - Direct stimulation of Candida proliferation }\end{array}$ \\
\hline \multicolumn{2}{|l|}{ Metabolic factors } \\
\hline $\begin{array}{l}\text { - Obesity } \\
\text { - Diabetes mellitus }\end{array}$ & $\begin{array}{l}\text { - } \uparrow \text { Adherence of Candida do vaginal cells } \\
\text { - } \uparrow \text { Levels of vaginal glycogen } \\
\text { - } \downarrow \text { Vaginal immunological response }\end{array}$ \\
\hline - Low zinc levels & - $\downarrow$ Cellular immunity \\
\hline \multicolumn{2}{|l|}{ Host factors } \\
\hline $\begin{array}{l}\text { - Immunosuppression (e.g. HIV) } \\
\text { - Debilitating illnesses } \\
\text { - Stress }\end{array}$ & - $\downarrow$ Immunological defences \\
\hline $\begin{array}{l}\text { - Genetic polymorphisms (MBL gene, IL4 gene, } \\
\text { NALP3, dectin-1 gene, CARD9, STAT1, STAT3) }\end{array}$ & - $\downarrow$ Immunological defences \\
\hline - ABO-Lewis nonsecretor blood type & $\begin{array}{l}\text { - } \downarrow \text { Inhibition of adherence lectins } \\
\text { - } \downarrow \text { IgA levels } \\
\text { - Carbohydrates metabolism abnormalities }\end{array}$ \\
\hline - Atopy/allergy history & - Excessive reaction to Candida antigens \\
\hline - Black race & - Genetic factors? \\
\hline \multicolumn{2}{|l|}{ Drugs } \\
\hline $\begin{array}{l}\text { - Antibiotics (topical and systemic) (mostly beta- } \\
\text { lactamics, macrolides, and tetracyclines) }\end{array}$ & - Elimination of protective vaginal flora (lactobacilli) \\
\hline $\begin{array}{l}\text { - Steroids } \\
\text { - Immunosuppressors } \\
\text { - Chemotherapy }\end{array}$ & - $\downarrow$ Immunological defences \\
\hline \multicolumn{2}{|l|}{ Behavioural factors } \\
\hline $\begin{array}{l}\text { - Hot and humid climates } \\
\text { - Tight and synthetic clothes } \\
\text { - Patny-liners (?) } \\
\text { - Obesity }\end{array}$ & - $\uparrow$ Moisture and temperature \\
\hline $\begin{array}{l}\text { - Bad hygienic habits } \\
\text { - Vaginal douching } \\
\text { - Swimming pools rich in chloride }\end{array}$ & $\begin{array}{l}\text { - } \uparrow \text { Spore load (from the intestinal reservoir) } \\
\text { - } \uparrow \text { Vaginal } \mathrm{pH} \\
\text { - Destruction of lactobacilli }\end{array}$ \\
\hline - Dietary factors (rapid sugars) & • $\uparrow$ Glycogen \\
\hline $\begin{array}{l}\text { - Sexual habits (frequent sexual intercourse, recipient } \\
\text { oral sex) (Controversial: early sexual debut, new or } \\
\text { multiple partners, intercourse during menses) }\end{array}$ & $\begin{array}{l}\text { - } \uparrow \text { Spore load } \\
\text { - Alteration of the flora by semen } \\
\text { - Exposure to cytokines, antigens, prostaglandins, and } \\
\text { antibodies from semen } \\
\text { - Transmission from the oral mucosa (?) }\end{array}$ \\
\hline - Copper IUDs/ LNG-IUS & $\begin{array}{l}\text { - Formation of biofilms, that increase adherence and act } \\
\text { as reservoirs } \\
\text { - Changes in the vaginal flora }\end{array}$ \\
\hline
\end{tabular}

VVC is not considered STI, but it is sexually related. Sexual intercourse and the deposition of semen in the vagina changes the $\mathrm{pH}$, the interleukin and prostaglandin milieu, exposes the vagina to $\operatorname{IgE}$ and antibodies from the male partner, which can be responsible for the development of symptoms of VVC.

\subsubsection{Signs and Symptoms}

The reservoir of Candida, during an active episode of VVC is the vagina, which is devoid of itch receptors, thus the symptoms manifest only in the vulva. It is not known, if itch is caused by the infection itself or secondary to the contact with the 
vaginal discharge. In severe cases, manifestations of VVC such as redness and oedema may extend up to the perianal area and the intercrural folds (Fig. 24.2). Satellite vulvar lesions can be present.

Itch is the most notorious symptom of $\mathrm{VVC}-$ but it must be kept in mind that most women with itching do not have a VVC [18]. Especially in cases of hypoestrogenism, in the absence of immunodepression, VVC is not likely to be the cause of itching.

Other symptoms can include entry dyspareunia, soreness, and irritation. The presence of NAC is usually asymptomatic; if not, it usually causes burning, rather than itching, and the symptoms tend to be milder.

Women can describe a more abundant, curdy, white and thick (cheese-like) or watery discharge, without an offensive smell (Fig. 24.1). It can also be absent, especially in chronic VVC.

Fissures and excoriations can cause vulvar pain and terminal or post-micturition dysuriaderived from the contact of urine with the lesions, rather than from urethral involvement. Oedema can be present, more exuberantly in the labia minora, and vulvar redness is seen in up to $40 \%$ of cases [2]. The vagina and cervix may be covered with a white, cheesy discharge (Fig. 24.2), but usually do not look inflamed and there is no cervicitis, but minor bleeding can be noticed if removal of the discharge plaque from the vaginal wall is attempted [2].

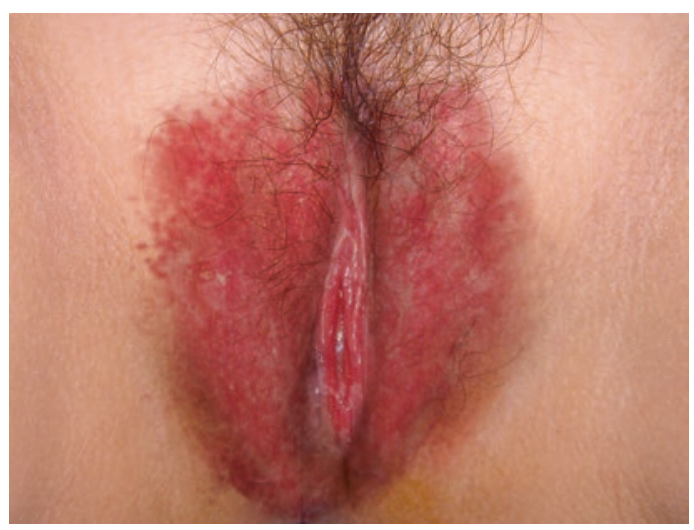

Fig. 24.2 Vulvovaginal candidiasis (VVC), with vulvar erythema in the interlabial sulci Courtesy of Professor Jacob Bornstein
The severity of symptoms can fluctuate along the menstrual cycle, worsening in the week prior to menses and improving during it. It can be explained by the vaginal epithelial cell proliferation and cytolysis, mediated by oestrogens and progesterone, respectively, which ultimately leads to increased levels of glycogen in the vagina. The raising of the $\mathrm{pH}$ mediated by the presence of blood and endometrial debris in the vagina leads to a decrease in the symptoms.

\subsubsection{Complications}

VVC, especially the complicated form, is a major cause of mental suffering, depression, low self-esteem, with impact on sexual and affective relations.

A large majority of newborns who are colonized with $C$. albicans during a vaginal delivery will develop oral candidiasis or napkin dermatitis during their first year of life. This can be diminished by treating colonized mothers during the 3rd trimester [2].

Petricevic et al. have found slight increases in preterm labour and risk of low birth weight rates, especially if colonization is present during the 2nd trimester of pregnancy [19].

Candida chorioamnionitis has been reported, but it is a very rare event and usually related to procedures such as in vitro fertilization, cérclage, or amniocentesis [20].

In one study, the presence of Candida was significantly associated with an increased risk of seroconversion in HIV negative women, with a seropositive male partner [21].

VVC has been associated with vulvodynia in several studies but most of the reported episodes are based on recall and not laboratory confirmed, thus making it unreliable. Nevertheless, long-term treatment with fluconazole is not an effective treatment of vulvodynia. Candida can, however, be the initial aggression to the vestibular mucosa and it has been shown that in vulvodynia patients the inflammatory response to it can be heightened [22]. 


\subsubsection{Diagnosis}

Clinical history and a vulvovaginal examination are fundamental parts of the diagnosis, but not sufficient. Self-diagnosis of VVC is wrong in up to $90 \%$ of cases and should not be encouraged [6, 23]. "Phone diagnosis" is also an unreliable approach.

The diagnosis is supported by wet mount microscopy (WMM), ideally using phase contrast microscopy [2] and, in some cases, by culture.

\subsubsection{Microscopy}

The most important tool in the diagnosis of VVC is microscopy, which should be performed systematically in women with suspected vulvovaginitis. Not only it allows the diagnosis of VVC, as it is the only way to identify the presence of mixed infections. WMM is cheaper than Gram staining and allows an immediate diagnosis.

There is evidence that collecting the sample from the anterior vaginal wall increases the likelihood of identifying Candida [24].

Candida in WMM can present as mycelium and/or blastospores. Mycelium includes both hyphae (filaments that compose the body of the fungus) and pseudohyphae (filaments composed of elongated budding cells that failed to detach) and their presence is highly suggestive of infection, rather than mere colonization (Fig. 24.3). However, some species, like C. glabrata, are unable to form mycelium. The blastospores of $C$. glabrata tend to cluster and to have the shape of a bowling pin or a "snowman" (Fig. 24.4). In the presence of clustering blastospores, in the absence of mycelium, NAC should be considered (Fig. 24.5) [4].

Care must be taken not to confuse sperms heads with blastospores. The former tend to be asymmetrical (larger where the tail was attached) and are bicolor (Fig. 24.6) [4].

Some authors recommend the addition of a drop of $\mathrm{KOH}$ to the slide, which dissolves the epithelial cells and leukocytes, but not the fungal structures, increasing the sensitivity of WMM to up to $85 \%[6,24]$. Other measures to try to improve the identification of these structures can include the staining with methylene blue [4].

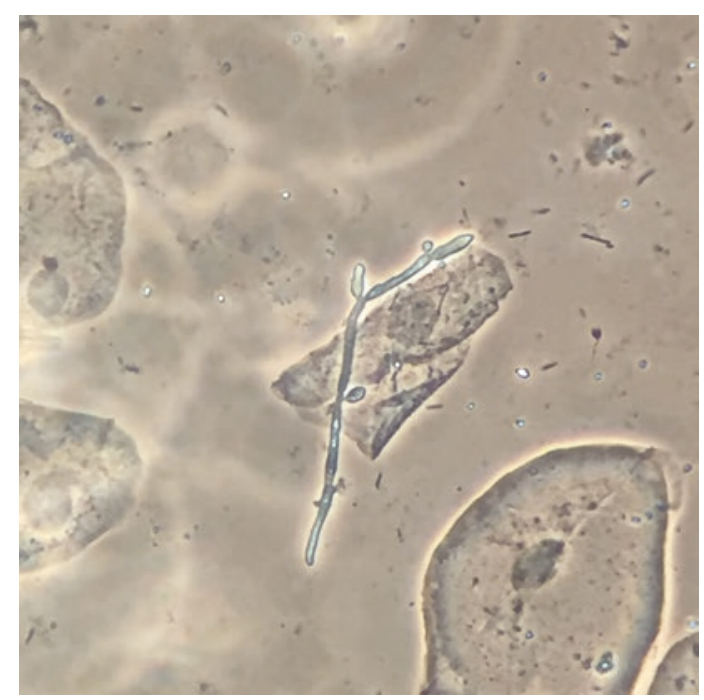

Fig. 24.3 C. albicans (pseudohyphae) in wet mount (phase contrast $400 \times$ ). The background flora is normal, despite some scarcity of lactobacilli. (phase contrast, $400 \times$ )

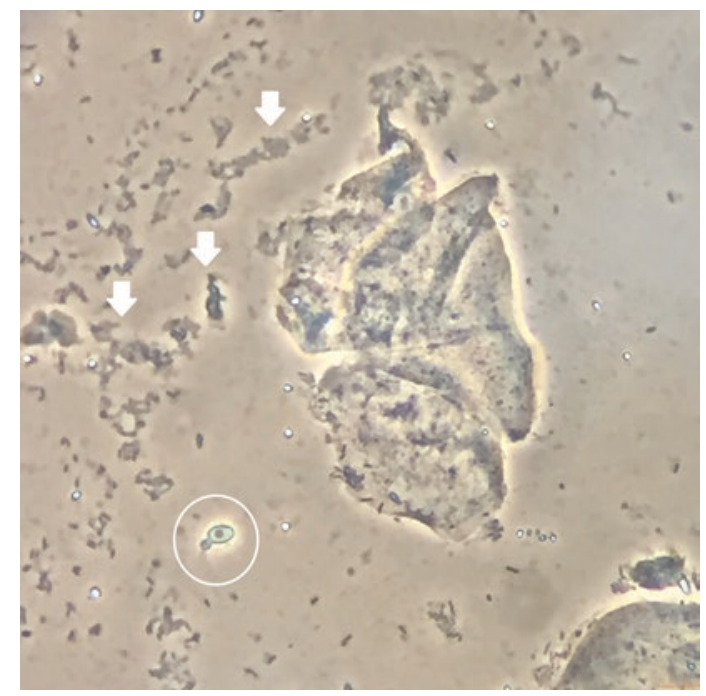

Fig. 24.4 "Snowman" typical of $C$. glabrata (inside the white circle). Anaerobic type background flora (white arrows). (phase contrast, $400 \times$ )

The Pap test is specific for the presence of Candida, but has a sensitivity of only $25 \%$, making it useless as diagnostic tool. This comes as no surprise, since it is a cervical rather than a vaginal sample [6]. 


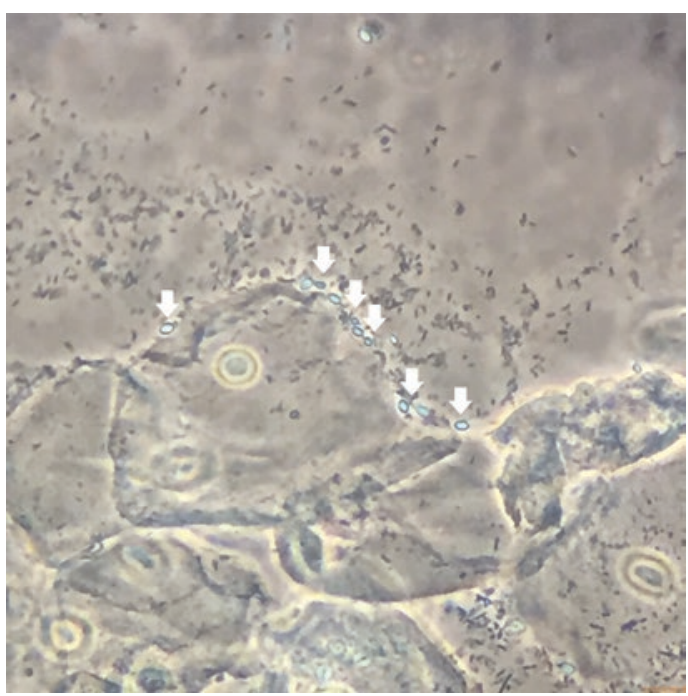

Fig. 24.5 Clustering of blastospores, typical of NAC (white arrows). (phase contrast, $400 \times$ )

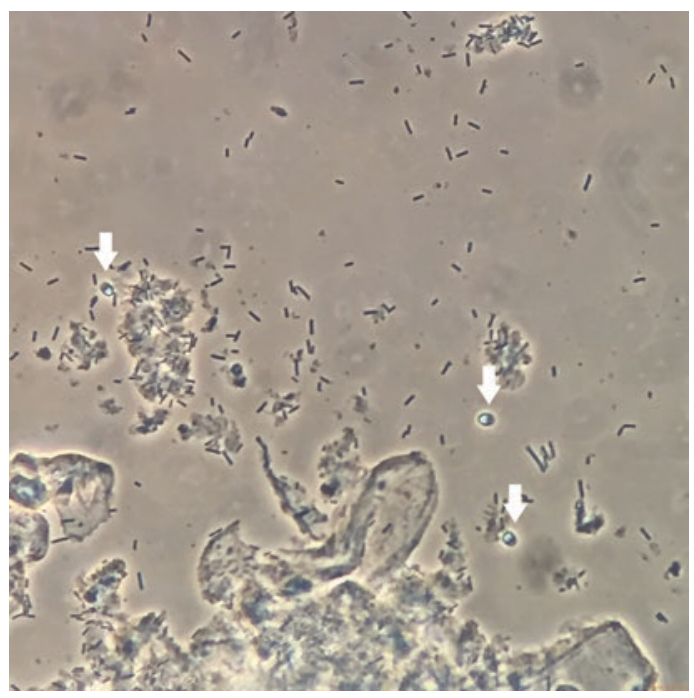

Fig. 24.6 Sperm heads, which can be mistaken by blastospores (white arrows). Notice that these are bicolor and asymmetrical. (phase contrast, 400×)

\subsubsection{Cultures}

Cultures are not needed routinely. Exceptions are recurrent episodes, microscopy negative or uncertain, or no response to treatment $[2,6]$. Sensitivity tests are hardly ever needed, except for difficult NAC cases. C. albicans strains resistant to fluconazole are uncommon and very rarely pose a clinical problem.
Identification of Candida in cultures, per se, cannot be assumed as a diagnosis of VVC, as it does not distinguish colonization from infection.

The swabs can be transported in common transport means (Stuart or Amies)—or even without it, at room temperature, and should be cultivated within $6 \mathrm{~h}$ [4]. There seems to be no advantage between the available culture means (Sabouraud agar, Nickerson medium, or Microstix-Candida medium) for Candida [6].

\subsubsection{3 $\mathrm{pH}$}

Candida is more often found with normal $\mathrm{pH}$ and is likely to be more symptomatic under those conditions. However, it may co-occur with BV or aerobic vaginitis (AV) (Fig. 24.4), which are typically associated with elevated $\mathrm{pH}$. An elevated $\mathrm{pH}$ cannot rule out VVC, and at the same time, typical clinical presentation with a normal $\mathrm{pH}$ does not necessarily confirm the diagnosis [4].

However, the $\mathrm{pH}$ can guide the next steps in the management of the patient with symptoms suggestive of VVC: If microscopy is positive for Candida and the $\mathrm{pH}$ is increased, a mixed infection must be considered; if microscopy is negative and $\mathrm{pH}$ is normal, cultures are recommended [6].

\subsubsection{Molecular Tests}

The Affirm VPIII is a commercially available test, based on DNA probes, that detects Candida, T. vaginalis, and $G$. vaginalis in vaginal samples, returning the result in $45 \mathrm{~min}$. The sensitivity and specificity for Candida, in comparison with the gold standard (culture) were $82.76 \%$ and $98.80 \%$, respectively $[25,26]$.

The use of nucleic acid amplification tests (NAAT) techniques increases the detection rate of Candida in 12.5\% [27] and can be an option in those cases of high grade of suspicion, in which wet mount and cultures are negative. In recurrent cases, when microscopy is positive but cultures are negative, molecular techniques lead to the diagnosis of three times more cases [28, 29].

More recently, the BD MAX system, a real time PCR test for the detection of the presence of DNA from lactobacilli, bacteria associated 
with BV, T. vaginalis, and Candida (C. albicans, C. tropicalis, C. parapsilosis, C. dubliniensis, C. glabrata, and C. krusei) was developed. Sensitivity for the different species of Candida ranged from $75-91 \%$ and specificity was higher than $90 \%$. It showed to perform similarly in selfcollected samples [30].

These tests allow for faster results, are less operator dependent, and can improve the diagnostic performance, but pose the risk of overdiagnosis (not distinguishing colonization from infection), not recognizing the full picture (mixed infections), and are still expensive.

\subsubsection{Treatment}

\subsubsection{General Principles}

Since the symptoms are mostly vulvar, women must be warned that topical medication must be applied inside the vagina, rather than (just) in the vulva. External, vulvar application can lead to transitory relief of symptoms, but not to cure.

Topical antifungals can be oil based and, consequently weaken condoms [10].

Oral azoles can interfere with oral anticoagulants (increasing its levels) and anticonvulsants, such as phenytoin.

There is no indication to treat sexual partners, unless they have symptoms themselves (balanitis); in the latter case, topical antifungals can be used. Redness, in some cases, may be associated with an allergic reaction to Candida antigens, rather than infection.

Persistence of symptoms can be the result of a contact dermatitis, resulting from the repeated and long lasting treatments, or from secondary lichen simplex chronicus. In some cases, allergy to propylene glycol, a common excipient in vaginal medications can develop.

\subsubsection{Asymptomatic Candida}

There is no reason to treat asymptomatic Candida in non-pregnant women, independently of being an incidental finding in a Pap test or other laboratorial exam, or being suspected during a clinical examination.

\subsubsection{Uncomplicated VVC}

These cases should be treated with short courses (1-7 days) of vaginal imidazoles (clotrimazole, miconazole, butoconazole, etc.) or single doses of oral triazoles (fluconazole or, alternatively, itraconazole), which have similar efficacy $(>80 \%)$ and adverse effects profiles [10] (Table 24.3). The choice for oral or topical routes is according to patients' preferences. In some cases, women find a faster relief by using vaginal formulations, as it temporarily increases the $\mathrm{pH}$.

There is no evidence that itraconazole is more effective than fluconazole [31, 32]. Topical polyenes, such as nystatin, have lower cure rates than topical imidazoles [33]. The limited data concerning the use of terbinafine, an allylamine antifungal suggests that it is efficacious if used topically, but not if orally $[34,35]$. Data about ciclopirox olamine is also limited, but the few trials in which it was used showed it to be safe and effective.

\subsubsection{Complicated VVC}

Severe cases of VVC should be treated with more prolonged courses of topical antifungals or, if fluconazole is chosen, a second dose after $72 \mathrm{~h}$ is recommended (Table 24.3).

Topical, low potency corticosteroids (hydrocortisone) for a couple of days can be helpful in very symptomatic patients.

Cases of recurrent VVC are a truly clinical challenge. Reasonable attempts to control or correct risk factors should be tried: reducing sugar intake, stopping hormonal contraceptives or removing IUDs/LVG-IUSs, correcting excessive washing, stopping the use of tight or synthetic clothes, etc. Each measure should be sequentially tried and, if not efficacious, suspendedotherwise, these changes will just add suffering to someone who already has an impaired quality of life due to a chronic disease $[4,6]$.

In case of failure of these measures, selftreatment of the episodes or, preferably, suppressive treatment must be considered. The most commonly recommended treatment was proposed by Sobel [36] and consists of taking $150 \mathrm{mg}$ of oral fluconazole weekly, for 6 months, after an induction in the first week (three times $150 \mathrm{mg}$ in the first week). Donders proposed an alternative 
Table 24.3 Treatment of VVC

\begin{tabular}{|c|c|c|}
\hline \multirow[t]{2}{*}{ Uncomplicated } & Topical (vaginal) & $\begin{array}{l}\text { Clotrimazole } 1 \% \text { cream } 5 \mathrm{~g} \text { id for } 7-14 \text { days } \\
\text { Clotrimazole } 2 \% \text { cream } 5 \mathrm{~g} \text { id for } 3 \text { days } \\
\text { Clotrimazole } 100 \mathrm{mg} \text { suppository, id for } 7 \text { days } \\
\text { Clotrimazole } 200 \mathrm{mg} \text { suppository, id for } 3 \text { days } \\
\text { Clotrimazole } 500 \mathrm{mg} \text { suppository, single application } \\
\text { Miconazole } 2 \% \text { cream } 5 \mathrm{~g} \text { id for } 7 \text { days } \\
\text { Miconazole } 4 \% \text { cream } 5 \mathrm{~g} \text { id for } 3 \text { days } \\
\text { Miconazole } 100 \mathrm{mg} \text { suppository, id for } 7 \text { days } \\
\text { Miconazole } 200 \mathrm{mg} \text { suppository, id for } 3 \text { days } \\
\text { Miconazole } 1200 \mathrm{mg} \text { suppository, single application } \\
\text { Tioconazole } 6.5 \% \text { ointment } 5 \mathrm{~g} \text { single application } \\
\text { Tioconazole } 300 \mathrm{mg} \text { suppository, single application } \\
\text { Butoconazole } 2 \% \text { cream (bioadhesive), } 5 \mathrm{~g} \text { in a single application } \\
\text { Terconazole } 0.4 \% \text { cream } 5 \mathrm{~g} \text { id for } 7 \text { days } \\
\text { Terconazole } 0.8 \% \text { cream } 5 \text { g id for } 3 \text { days } \\
\text { Terconazole } 80 \mathrm{mg} \text { suppository, id } 3 \text { days } \\
\text { Econazole } 150 \mathrm{mg} \text { tablets, } \text { id for } 3 \text { days } \\
\text { Nystatin } 100.000 \text { units suppositories } i d \text { for } 14 \text { days } \\
\text { Ciclopirox olamine } 1 \% \text { cream } 6 \text { days }\end{array}$ \\
\hline & Oral & $\begin{array}{l}\text { Fluconazole } 150 \mathrm{mg} \text {, single dose } \\
\text { Itraconazole } 200 \mathrm{mg} \text { id, } 3 \text { days } \\
\text { Itraconazole } 200 \mathrm{mg} 2 \mathrm{id} \text {, one day } \\
\text { Ketoconazole } 200 \mathrm{mg} 2 \mathrm{id}, 5 \text { days (hepatic toxicity) }\end{array}$ \\
\hline Pregnancy & \multicolumn{2}{|c|}{ Only topical azoles during 7 days } \\
\hline Breastfeeding & \multicolumn{2}{|c|}{ Azoles excreted in milk; avoid during breastfeeding } \\
\hline \multirow[t]{2}{*}{ Severe VVC } & Topical & Prolong treatment for $7-14$ days \\
\hline & Oral & Fluconazole $150 \mathrm{mg}$ day 1 and day 4 \\
\hline \multirow[t]{3}{*}{ Recurrent VVC } & $\begin{array}{l}\text { Fluconazole } \\
\text { suppression for } \\
12 \text { months (ReCiDiF) }\end{array}$ & $\begin{array}{l}\text { Phase } 1-200 \mathrm{mg} \text { po days } 1,4 \text { and } 7 \\
\text { Phase 2-200 mg po once a week for } 2 \text { months } \\
\text { Phase 3-200 mg po once every other week for } 4 \text { weeks } \\
\text { Phase 4-200 mg po once a month for } 6 \text { months } \\
\text { Transition from one phase to the other implies: Symptoms free, wet } \\
\text { mount/culture negative }\end{array}$ \\
\hline & $\begin{array}{l}\text { Fluconazole } \\
\text { suppression for } \\
6 \text { months (Sobel) }\end{array}$ & $\begin{array}{l}150 \mathrm{mg} \text { po once a week }(100,150 \text { or } 200 \mathrm{mg} \text { on day } 1,4 \text { and } 7 \text {, prior to } \\
\text { suppressive therapy) }\end{array}$ \\
\hline & $\begin{array}{l}\text { Depot } \\
\text { medroxyprogesterone } \\
\text { acetate }\end{array}$ & Intramuscular $150 \mathrm{mg}$ every 12 weeks \\
\hline \multirow[t]{4}{*}{$\begin{array}{l}\text { Non-albicans } \\
\text { VVC }\end{array}$} & $\begin{array}{l}\text { Boric acid } 600 \mathrm{mg} \\
\text { vaginal capsules }\end{array}$ & $\begin{array}{l}\text { Vaginally } i d \text { for } 2 \text { weeks } \\
\text { Must be compounded by pharmacists } \\
\text { Toxic if per mouth } \\
\text { Maintenance regimen? }\end{array}$ \\
\hline & Gentian violet & $\begin{array}{l}\text { Useful in some cases } \\
\text { Good antipruritic effect } \\
\text { Messy }\end{array}$ \\
\hline & $\begin{array}{l}\text { High dose } \\
\text { fluconazole }\end{array}$ & $800 \mathrm{mg}$ id for $2-3$ weeks \\
\hline & \multicolumn{2}{|c|}{$\begin{array}{l}\text { Other options may include: } \\
\text { - Flucytosine } \\
\text { - Posaconazole } \\
\text { - Voriconazole } \\
\text { - Amphotericin B } \\
\text { - Caspofungin } \\
\text { - Micafungin }\end{array}$} \\
\hline
\end{tabular}


regimen, after the $\mathrm{ReCiDiF}$ trial, lasting 1 year and consisting of progressively increased intervals between fluconazole intake (see scheme in Table 24.3) [28]. In the later, while using the same total dosage of fluconazole and being comparable in terms of efficacy at 6 months, $77 \%$ of women were disease free at 12 months, comparing to only 42.9\% in the Sobel's scheme [28, 36].

Episodes during suppressive therapy can be managed with topical antifungals; in occasional cases, antihistamines can be helpful.

Dennerstein reported good results in controlling the symptoms by using depomedroxyprogesterone, probably by inducing a hypoestrogenic state [37]. In our hands, it has been an excellent option when other options fail.

It can be advisable that these patients have swabs with them, for self-collection and confirmation of the episodes.

In difficult cases, consider exclusion of HIV and diabetes.

In women with history of frequent or recurrent VVC after antibiotic intake, beta-lactamics, macrolides, and tetracyclines should be avoided. For urinary tract infections, alternative options include fosfomicine or norfloxacine. Additionally, prophylactic antifungals can be prescribed, to be taken at the beginning and halfway through the course of antibiotics [4].

The most common of the NACs, C. glabrata, is not sensible to the usual antifungals. One of the best alternatives is boric acid. Patients must be warned of its toxicity if ingested (gastrointestinal, mental disorders, seizures, anaemia, etc.).

C. krusei is intrinsically resistant to oral triazoles, however, it responds well to topical imidazoles, nystatin, boric acid, and ciclopirox olamine [2].

\subsubsection{Candida in Pregnancy}

Oral triazoles should not be used during pregnancy, as it has been related to spontaneous abortion and to a slight increase in the risk of Fallot's tetralogy.

As discussed previously, Candida can be associated with negative obstetrical outcomes and for that reason some authors recommend treatment of asymptomatic women. This recommendation, however, is not universal and more data is needed to support it.

\subsubsection{Future Perspectives}

Despite the role played by lactobacilli in the prevention of symptomatic VVC, its administration either as treatment or adjuvant of antifungal treatment, has not shown to be useful in acute or recurrent episodes [38]. This line of investigation, however, can prove to have some role in the future, especially if strains that naturally dominate the vagina of healthy women are used.

In the future, vaccines may be the answer to treat recurrent VVC.

\subsubsection{Saccharomyces cerevisiae}

The yeast $S$. cerevisiae can colonize the vagina of healthy women, and very rarely, become symptomatic. Its incidence, however, seems to be rising and, apparently it is not always associated with professional exposure (brewery or bakery) or with consumption of it as a food additive or probiotic [39, 40].

Symptoms are undistinguishable from those of VVC. It is, however, less susceptible to antifungals and is associated with high rates of recurrence. The diagnosis is confirmed by culture, but can be suspected when larger than usual blastospores are seen on WMM [4] (Fig. 24.7). Treatment options can include nystatin, amphotericin B, flucytosine, and boric acid.

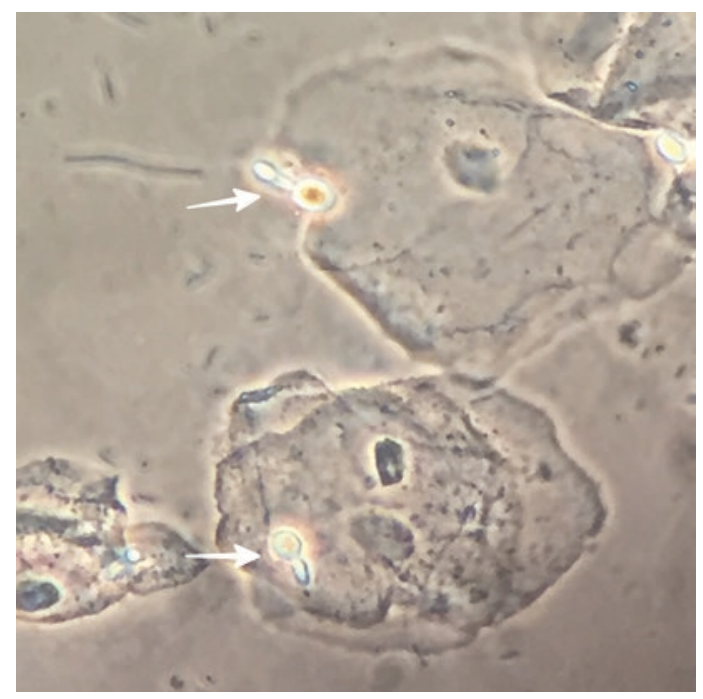

Fig. 24.7 Larger than usual budding blastospores (white arrows). Culture confirmed $S$. cerevisiae 


\subsection{Trichomoniasis}

\section{Trichomoniasis: Breaking the Myths}

- Trichomoniasis is not rare-it is the most common non-viral STI and prevalence seems to be rising.

- The classical image of the "strawberry cervix" is seen in less than $5 \%$ of the cases with $T$. vaginalis

- Maternal Trichomonas vaginalis infection is not only a nuisance. It is a risk factor for low birth weight, premature rupture of membrane, preterm labour, and even intellectual disability. One study related $T$. vaginalis with neonatal death.

\subsubsection{Aetiology and Pathophysiology}

Trichomoniasis is caused by the extracellular protozoan Trichomonas vaginalis, which was first described in 1836, but forgotten in the medical literature for a century.

T. vaginalis is of piriform, round or amoeboid shape, with a distinctive elongated nucleus, four anterior flagella, and a large posterior axostyle to which an undulant membrane is attached. It is motile, with fast and erratic movements.

The amitochondriate and anaerobic parasite is capable of phagocyting bacteria (including lactobacilli), epithelial cells, and erythrocytes (from where it gets iron and cholesterol), but can itself be phagocyted by macrophages [41].

Its only natural hosts are humans, colonizing almost exclusively the genitourinary tract of both men and women. Infection sites in women include the vagina, endocervix, urethra, and paraurethral glands. Very rarely it can be found in the respiratory tract.

In adults, transmission is almost exclusively by sexual route; direct vaginal or urethral inoculation is needed. There are some reports of possible transmission by sharing the bath water, per fomites, or by genital manipulation by another infected person. The parasite can survive outside of the human body for periods of around $3 \mathrm{~h}$, if protected from desiccation [42].

T. vaginalis can be infected by double strand RNA viruses, which, as discussed ahead, can have severe implications in its virulence [43].

\subsubsection{Prevalence and Epidemiology}

Trichomoniasis is the most common non-viral STI and prevalence seems to be rising [44, 45]. Existing projections are likely to be an underestimation of the true prevalence and burden of the infection, as it is not a reportable disease. This leaves extensive gaps in the understanding of the dynamics of the infection and the true extent of its complications.

Different diagnostic techniques and baseline characteristics of the populations studied preclude comparisons between series. For instance, the very high prevalences found in STI clinics are unlikely to reflect the true picture for the general population [7].

According to World Health Organization, in 2008 , in the age range 15-49 years, trichomoniasis led the list of curable STIs, with 276.4 million of new cases in that year: more than the sum of those of Chlamydia trachomatis, Neisseria gonorrhoea and syphilis. The estimated number of T. vaginalis infections at any moment was estimated at 187 million (Table 24.4).

The prevalence is much higher in females $(5.6-22.0 \%)$ than in males (0.6-2.2\%) (Table 24.4). Incidence, however, is similar in both sexes, ranging between 45.6 and 180.60/00 (promil) [45], meaning that the rate of transmis-

Table 24.4 Prevalence and incidence of $T$. vaginalis in 2008, according to the WHO. Adapted from Rowley et al. [45]

\begin{tabular}{l|c|l|l|l}
\hline \multirow{2}{*}{ WHO region } & \multicolumn{3}{|c|}{ Incidence $\left(\%_{0}\right)$} & \multicolumn{2}{l}{ Prevalence $(\%)$} \\
\cline { 2 - 5 } & Female & Male & Female & Male \\
\hline African & 146.0 & 164.8 & 20.2 & 2.0 \\
\hline Americas & 177.7 & 180.6 & 22.0 & 2.2 \\
\hline South East-Asia & 40.3 & 50.1 & 5.6 & 0.6 \\
\hline European & 51.7 & 48.4 & 5.8 & 0.6 \\
\hline $\begin{array}{l}\text { Eastern } \\
\text { Mediterranean }\end{array}$ & 64.0 & 66.1 & 8.0 & 0.8 \\
\hline Western Pacific & 45.6 & 47.0 & 5.7 & 0.6 \\
\hline
\end{tabular}


sion and acquisition is similar, but males spontaneous eliminate the infection much faster. It usually takes about 10-21 days in males, while in women it can persist for months or even years [46]. However, in men it too can become chronic or reinfection can occur. The zinc rich milieu of prostatic secretions can account for these differences; chronic infection in men is more likely in those with lower concentrations of zinc in the prostatic secretions [47].

Transmission is more effective from males to female than the other way round ( $T$. vaginalis is positive in $66-100 \%$ of the female partners of infected men vs. $30-80 \%$ of the male partners of infected women [48]).

The incubation period is believed to range between 4 and 28 days [49].

Contrary to other STIs, the prevalence of T. vaginalis, at least in some settings, peaks in women after 40 years of age. Possible explanations include: (1) long-standing infection in reservoirs, such as the periurethral and subepithelial glands, (2) increasing resistance to metronidazole, (3) increased $\mathrm{pH}$, due to the falling oestrogen levels, (4) sexual risk factors, and (5) screening artefact. The theory of sexual risk factors is supported by the fact that this peak was also described in men, and in women it only occurred in those who were also positive for high-risk human papillomavirus (HPV) [50].

\subsubsection{Risk Factors and Associations}

Despite geographical variations, racial, social, sexual, and behavioural factors for trichomoniasis have been identified, disentanglement of the various factors in order to distinguish true risk factors from mere associations is a nearly impossible task.

In the United States, the prevalence of trichomoniasis in women of black race was four times higher than in the general population and, more striking, ten times higher than white nonHispanic women.

In the same study, positive correlations were found with lower educational level, poverty, greater number of sexual partners, increasing age, and vaginal douching [51]. Other reported factors include early sexual debut, new or multiple sexual partners, having other STIs, incarceration, commercial sex, being an immigrant, intravenous drug use, cigarette smoking, and not using condoms [51, 52].

Sexual factors, per se, cannot account for the full explanation of the different prevalences found in different countries: for instance, European countries with rates of Chlamydia similar to those found in the United States have lower rates of TV [41].

One interesting association is that of $T$. vaginalis with BV, which is found in $60-80 \%$ of cases. The mechanism is not fully understood: on one side, $T$. vaginalis benefits from the increased $\mathrm{pH}$ and anaerobic environment associated with $\mathrm{BV}$, and, on the other side, T. vaginalis may disturb the vaginal microbiome and shift it to the anaerobic side [7].

\subsubsection{Signs and Symptoms}

It is estimated that up to $80-85 \%$ of infected women and $77 \%$ of men are asymptomatic [41, $45,48]$. Many of the asymptomatic women eventually become symptomatic-sometimes in a very exuberant, highly symptomatic way. Given the long periods during which the infection can be asymptomatic, it is almost impossible to ascertain when infection was acquired.

When symptomatic, women can refer a yellow or green discharge, frequently with a foul smell. Urinary symptoms can be present (frequency, dysuria), as well as lower abdominal pain, dyspareunia, vulvar irritation, itching, and burning. Dysuria, unlikely in women with VVC is not only terminal or post-micturition, as there can be a real urethritis or cystitis (urethral involvement occurs in $90 \%$ of cases) [53]. Symptoms tend to worsen during menses, probably due to the increase in the number of parasites, associated with the phagocytosis of erythrocytes.

Some women may suffer from postcoital bleeding, as a consequence of the presence of erosions in the vaginal wall.

On physical examination, this discharge is frothy, more or less abundant and fluid (Fig. 24.8). Erosions, cervical friability, and vaginal enantema 


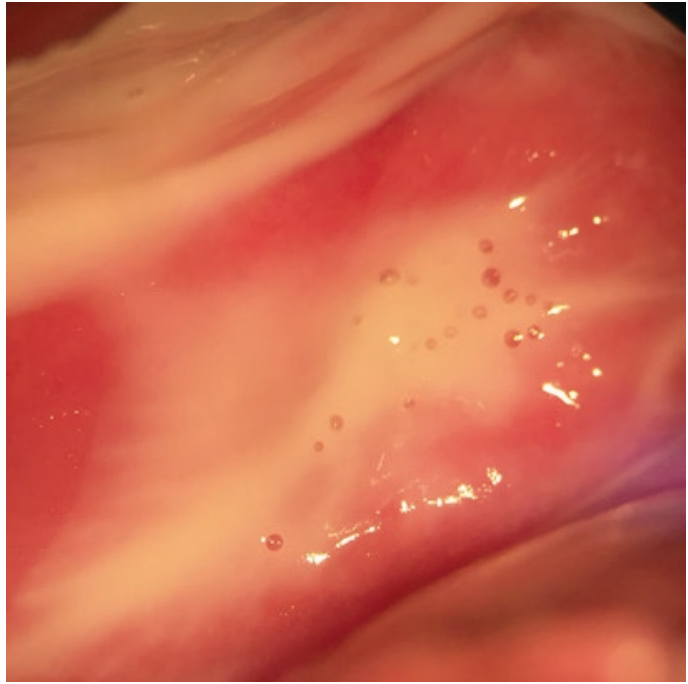

Fig. 24.8 Frothy vaginal discharge in a woman with Trichomonas vaginalis and bacterial vaginosis

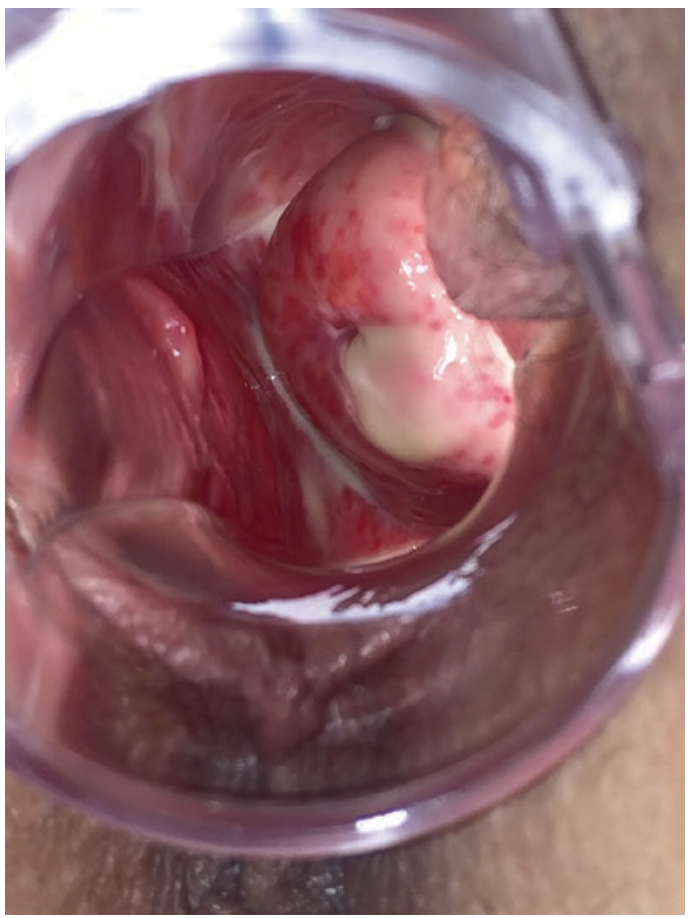

Fig. 24.9 Strawberry cervix, typical of a Trichomonas infection

can be noticed in the vaginal walls and the cervix. The classical image of the "strawberry cervix" is uncommon $(<5 \%)$ (Fig. 24.9); after the application of Lugol's solution it may gain the typical appearance of "Leopard skin" (Fig. 24.10).

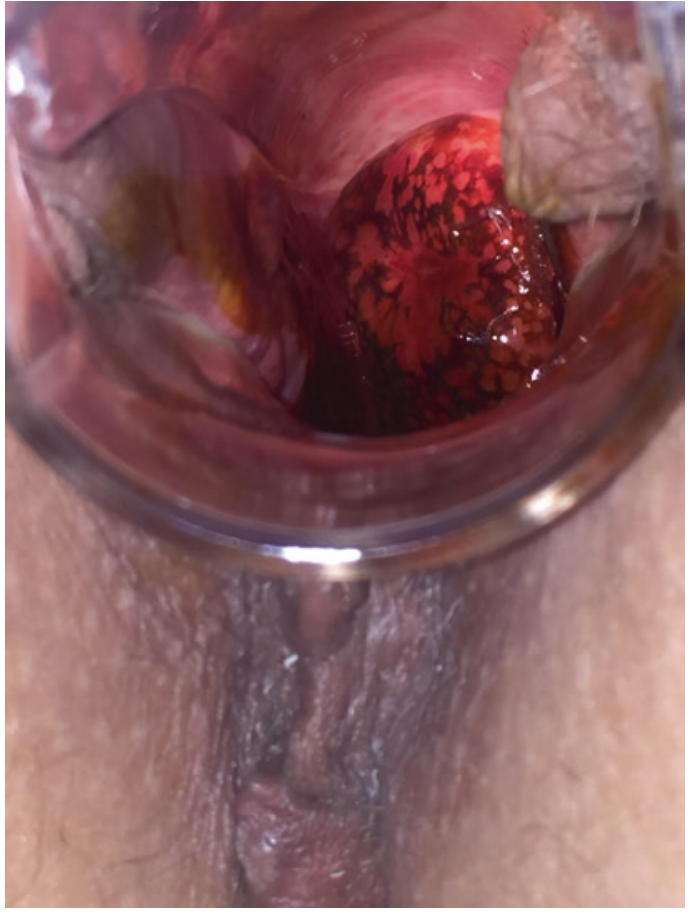

Fig. 24.10 Strawberry cervix after the application of iodine ("leopard skin")

Very rarely, T. vaginalis can be associated with the enigmatic condition of emphysematous vaginitis, in which air bubbles form in the vaginal walls, sometimes with crepitus during intercourse or speculum examination [54].

A normal gynaecological examination is not sufficient to exclude the presence of $T$. vaginalis.

\subsubsection{Complications}

For a long time, T. vaginalis was considered a nuisance STI. However, nowadays, it is acknowledged as being associated with severe complications, and considered a public health issue [41].

Maternal T. vaginalis infection is a risk factor for low birth weight (RR, 1.51; [95\% confidence interval $1.32-1.73, p<0.001]$ ), premature rupture of membranes (RR, 1.41; [95\% confidence interval, $1.10-1.82, p=0.007])$, preterm labour (RR 1.4 [95\% confidence interval, 1.15-1.75; $p=0.001]$ ) [55], and even intellectual disability [41]. One study related T. vaginalis with neonatal death $(1.6 \%$ vs. $0.8 \%, p=0.005)$ [56]. 
T. vaginalis infected with $M$. hominis, besides being more cytopathogenic, induce an increased production of IL1 $\beta$, IL6, IL8, and tumour necrosis factor (TNF) $1 \alpha-\mathrm{a}$ similar profile to that associated with preterm labour [57].

Newborns from infected mothers can have a self-limiting vaginitis or pneumonia, but sometimes treatment is required. The symptoms of vaginitis usually disappear as the levels of oestrogens wane.

T. vaginalis is a well-recognized risk factor for the transmission and acquisition of other STIs, namely HIV [58]. T. vaginalis increases the risk of acquisition and transmission by several ways: (1) by attracting inflammatory cells to the vagina, (2) by causing breaches in the integrity of the vagina and cervix (facilitating the access of HIV to the bloodstream), (3) by increasing IL-8, which increases HIV1 replication, and (4) by changing the vaginal flora towards BV [41].

Proper management of HIV patients should include regular screening of trichomoniasis (and BV), as it can be asymptomatic and still increase the HIV load in the vagina, as thus promote the transmis- sion. Reducing T. vaginalis rates can be an effective, cost-effective measure to reduce HIV transmission, especially in populations such as in sub-Saharan Africa (Table 24.4), where it is believed to increase the risk of infection 2.1-2.8 times; this impact can be extensive to vertical transmission [59].

It has also been linked to increased risk of pelvic inflammatory disease, HSV2, persistence of HPV infection and cervical cancer, and false positive abnormal Pap tests [43, 44, 60]. Some authors claim it should be included in the carcinogenic agents list (increased risk of cervical and prostate cancer) [43].

T. vaginalis infections out of the genitourinary tract are very rare, but a few cases have been described, including a central nervous infection in a premature neonate, leading to death [61].

\subsubsection{Diagnosis}

Given the burden of complications associated with $T$. vaginalis, low threshold for testing and sensitive tests should be used (Table 24.5).

Table 24.5 Available tests for the diagnosis of T. vaginalis

\begin{tabular}{|c|c|c|c|c|}
\hline \multicolumn{2}{|l|}{ Type of test } & \multirow{2}{*}{$\begin{array}{l}\text { Sensitivity } \\
36-82 \%\end{array}$} & \multirow{2}{*}{$\begin{array}{l}\text { Specificity } \\
100 \%\end{array}$} & \multirow[b]{2}{*}{$\begin{array}{l}\text { Notes } \\
\text { - Results in a few minutes } \\
\text { - Easy and cheap } \\
\text { - Low sensitivity } \\
\text { - Exam must be performed } \\
\text { immediately } \\
\text { - Not useful in men }\end{array}$} \\
\hline Wet mount microscopy & & & & \\
\hline Pap test & & $56-76 \% \%$ & $>95 \%$ & $\begin{array}{l}\text { - Not recommended for } \\
\text { screening } \\
\text { - Liquid based cytology } \\
\text { performs better than } \\
\text { classical cytology } \\
\text { - Controversial if further } \\
\text { testing is needed before } \\
\text { treatment }\end{array}$ \\
\hline Culture & $\begin{array}{l}\text { Modified } \\
\text { diamond medium } \\
\text { InPouch } \\
\text { (biomed } \\
\text { diagnostics, } \\
\text { White City, } \\
\text { Oregon) }\end{array}$ & $75-96 \%$ & $>95 \% \%$ & $\begin{array}{l}\text { - Not easily available } \\
\text { - Results in up to } 7 \text { days for } \\
\text { diamond medium } \\
\text { - Vaginal secretions preferred } \\
\text { - In InPouch, most positive } \\
\text { results occur within } 3 \text { days, } \\
\text { but } 17 \% \text { only after that } \\
\text { - InPouch has increased } \\
\text { sensitivity over traditional } \\
\text { culture mediums (?) } \\
\text { - Useful if resistance tests are } \\
\text { to be performed }\end{array}$ \\
\hline
\end{tabular}


Table 24.5 (continued)

\begin{tabular}{|c|c|c|c|c|}
\hline \multicolumn{2}{|l|}{ Type of test } & \multirow{2}{*}{$\begin{array}{l}\text { Sensitivity } \\
82-95 \%\end{array}$} & \multirow{2}{*}{$\begin{array}{l}\text { Specificity } \\
>95 \%\end{array}$} & \multirow[b]{2}{*}{$\begin{array}{l}\text { Notes } \\
\text { - Results in 10-15 min } \\
\text { - Does not allow to test for } \\
\text { other STIs } \\
\text { - False positives possible } \\
\text { - Self-testing possible } \\
\text { (decreased sensitivity) [62] }\end{array}$} \\
\hline $\begin{array}{l}\text { Immunochromatographic } \\
\text { assays }\end{array}$ & $\begin{array}{l}\text { OSOM (Sekisui, } \\
\text { Framingham, } \\
\text { MA) }\end{array}$ & & & \\
\hline DNA probes & $\begin{array}{l}\text { Affirm VPIII } \\
\text { (BD, Sparks, } \\
\text { MD) }\end{array}$ & $46.3-63 \%$ & $>95 \%$ & $\begin{array}{l}\text { - Results in }<1 \mathrm{~h} \\
\text { - Concomitant test for } C \text {. } \\
\text { albicans, G. vaginalis and } \\
\text { T. vaginalis } \\
\text { - Useful in settings where } \\
\text { STIs are not prevalent } \\
\text { - FDA approved }\end{array}$ \\
\hline \multirow[t]{7}{*}{ NAATs } & $\begin{array}{l}\text { AmpliVue } \\
\text { (Quidel, San } \\
\text { Diego, CA) }\end{array}$ & $>90 \%$ & $>95 \%$ & $\begin{array}{l}\text { - Results in } 45 \text { min } \\
\text { - Good agreement with PCR } \\
\text { - False positives possible? } \\
\text { FDA approved }\end{array}$ \\
\hline & $\begin{array}{l}\text { Solana (Quidel, } \\
\text { San Diego, CA) }\end{array}$ & $89.7 \%$ & $>95 \%$ & $\begin{array}{l}\text { - Results in }>45 \mathrm{~min} \\
\text { - FDA approved }\end{array}$ \\
\hline & $\begin{array}{l}\text { Aptima } T . \\
\text { vaginalis } \\
\text { (Hologic, San } \\
\text { Diego, CA) }\end{array}$ & $>95 \%$ & $>95 \%$ & $\begin{array}{l}\text { - Results in }<8 \mathrm{~h} \\
\text { - Possible cotest of } \mathrm{CT} / \mathrm{NG} \\
\text { - FDA approved }\end{array}$ \\
\hline & $\begin{array}{l}\text { In-house real } \\
\text { time PCR }\end{array}$ & $76-98 \%$ & $>95 \%$ & $\begin{array}{l}\text { - Better performance if } \\
\text { vaginal swabs are used }\end{array}$ \\
\hline & $\begin{array}{l}\text { XPert } T \text {. } \\
\text { vaginalis } \\
\text { (Cepheid, } \\
\text { Sunnyvale, CA) }\end{array}$ & $\begin{array}{l}95 \% \text { agreement } \\
\text { with in-house } \\
\text { PCR }\end{array}$ & $\begin{array}{l}100 \% \\
\text { agreement with } \\
\text { in-house-PCR }\end{array}$ & $\begin{array}{l}\text { - Results in } 60 \mathrm{~min} \\
\text { - FDA approved }\end{array}$ \\
\hline & $\begin{array}{l}\text { BD ProbeTec } Q^{\mathrm{x}} \\
\text { (BD, Sparks, } \\
\text { Maryland) }\end{array}$ & $>95 \%$ & $>99 \%$ & $\begin{array}{l}\text { - Results in }<8 \mathrm{~h} \\
\text { - FDA approved }\end{array}$ \\
\hline & $\begin{array}{l}\text { BD MAX system } \\
\text { (BD, Sparks, } \\
\text { Maryland) }\end{array}$ & $>90 \%$ & $>99 \%$ & Results in $3 \mathrm{~h}$ \\
\hline
\end{tabular}

However, that is not the reality most of the times [63]. When comparing studies, it is important to keep in mind if the gold standard used was wet mount/cultures or the much more sensitive NAATs, as these can detect even non-viable protozoans and low loads of microorganisms.

Wet mount microscopy can allow the immediate diagnosis, besides being a cheap and easy technique. However, it relies on documenting motile protozoans (https://www.youtube.com/ watch? v=pTL-_Q4S1Og). The observation should be performed immediately after collection of the sample; heating slightly the slide can increase the motility of the parasite. Immotile parasites are difficult to identify, as they have approximately the same size as a leucocyte.
Inflammation is not always present (Fig. 24.11), but when present it can be very exuberant. Wet mount microscopy has a rather low sensitivity (36-82\%) [64-67], even if using phase contrast and with experienced examiner. The sensitivity may be even lower in asymptomatic women, thus it cannot be recommended as a screening test. However, it can be used in a "cascade" model for symptomatic women: If it is diagnostic for T. vaginalis, treatment can be provided immediately; if negative, further laboratory testing must be carried out. Nevertheless, it is an excellent tool to check for the commonly associated presence of BV (Fig. 24.12).

Determination of $\mathrm{pH}$ is not a diagnostic tool, but it can work as a triage test; in symptomatic 


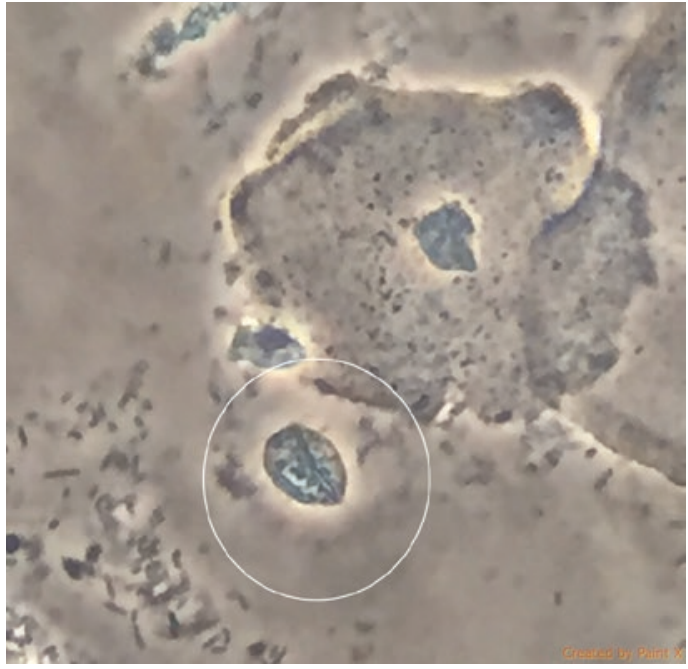

Fig. 24.11 Trichomonas vaginalis (inside white circle) (phase contrast, 400x)

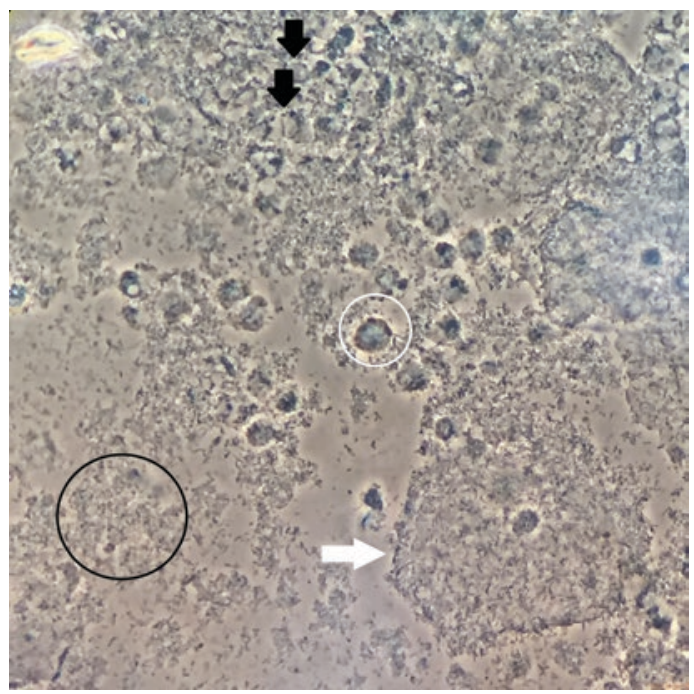

Fig. 24.12 Trichomonas vaginalis (white circle) and bacterial vaginosis (granular flora-black circle; clue cell-white arrow). Notice the presence of inflammation (black arrows), which is not a feature of BV (phase contrast, $400 \times$ )

trichomoniasis values are higher than 4.5 (frequently even higher than 5) [42]. The sensitivity of $\mathrm{pH}$ for the diagnosis of trichomoniasis is very high, but the predictive positive value is very low.

The Whiff test is frequently positive, as the coexistence $T$. vaginalis and BV is very high (60-80\%). However, a negative test does not exclude the diagnosis.
The Pap test should not be performed with the objective of diagnosing trichomoniasis. It is controversial if the finding of T. vaginalis in a Pap test should be confirmed prior to treatment: Some defend that no further testing is needed if liquid based cytology was used (as specificity is high), while others only accept it in settings where the disease is very prevalent $(>10 \%)$ [64], and others recommend systematic confirmation [10]. If the diagnosis was made in a conventional Pap test, confirmation should always be performed prior to treatment. In one study from 1972, comparing Pap test to cultures for the diagnosis of trichomoniasis, it was concluded that the former yielded high rates of false negative and false positive results, making it highly unreliable. It was assumed that the source of mistake was the rounded forms that the protozoan can assume, and that are difficult to distinguish from leukocytes [68].

Optimal tests for T. vaginalis in terms of sensitivity are NAATs, which can detect 3-5 times more infections than WMM [10]. These tests, however, are expensive and do not produce an immediate result-which is of utmost importance in STI clinics.

Vaginal and endocervical specimens (swabs or liquid based cytology mediums) are the best sampling options. With the use of urine samples, sensitivity drops slightly [66].

In the future, versatile platforms such as the XPert T. vaginalis (Cepheid, Sunnyvale, CA) [69] can gain terrain in this field: The results are rapid (60 $\mathrm{min}$ ) and the cartridge system allows the performance of different analysis using the same platform.

Point of care tests such as OSOM (Sekisui, Framingham, MA) or Affirm VPIII (BD, Sparks, MD) may represent an intermediate option, with a good performance, but cheaper than NAAT tests and allowing faster results, without the need for complex laboratory facilities.

\subsubsection{Treatment}

Treatment must be considered in all cases, as even if asymptomatic; T. vaginalis must not be seen as a commensal. The objectives of treating 
all cases are: the elimination of symptoms, stopping transmission, and reducing HIV risk.

As male partners of infected women have a high rate of infection [48], simultaneous treatment of those partners without need for confirmatory testing is mandatory.

The standard recommended treatment is a single dose of $2 \mathrm{~g}$ of metronidazole or tinidazole. Sexual abstinence for 1 week is recommended.

Patients must be advised to avoid alcohol consumption, as a disulfiram effect is possible for up to $24 \mathrm{~h}$ after taking metronidazole and $72 \mathrm{~h}$ after tinidazole; however, this risk may be overemphasized in the literature [70]. The most common secondary effects of nitroimidazoles are gastrointestinal symptoms (nausea, vomiting, metallic taste), headache, and dizziness). These are dose dependent and, for that reason, multi-dose schemes, are better tolerated. On the other hand, the compliance is higher for single dose schemes [71].

The success rate of cure with oral metronidazole is high (>90\%). Resistance, defined as a failure to eradicate the infection after two consecutive courses of treatment, is a raising problem, estimated to be of up to 5\% [71]. For tinidazole it is lower (1\%) [10]. Possible factors involved in resistance include: inactivation of metronidazole by vaginal bacteria, inadequate local concentration, and low zinc concentration [47]. It must be kept in mind, however, that many apparent failures of treatment are due to reinfection and non-compliance.

Zinc sulphate douches have been tried in small series, with good efficacy; however, it has been reported that it can cause cervical ulcerations [47] (Table 24.6).

Table 24.6 Treatment options for trichomoniasis

\begin{tabular}{|c|c|c|}
\hline \multirow[t]{2}{*}{ First choice } & Metronidazole & - 2 g per os, single dose \\
\hline & Tinidazole & $\begin{array}{l}\text { - } 2 \text { g per os, single dose } \\
\text { - Longer half-life } \\
\text { - More expensive } \\
\text { - Better intestinal tolerance }\end{array}$ \\
\hline \multirow[t]{2}{*}{ Alternative regimen } & Metronidazole & $\begin{array}{l}\text { - } 500 \mathrm{mg} 2 \text { id for } 7 \text { days (similar cure rates to } \\
\text { single dose schemes) } \\
\text { - Better tolerance }\end{array}$ \\
\hline & $\begin{array}{l}\text { Metronidazole } 750 \mathrm{mg} / \mathrm{miconazole} \\
200 \mathrm{mg}\end{array}$ & $\begin{array}{l}\text { - Vaginal application } 2 \text { id for } 7 \text { days } \\
\text { - Only if oral schemes not tolerated } \\
\text { - Very limited data on efficacy (one study) }\end{array}$ \\
\hline $\begin{array}{l}\text { In case of allergy to } \\
\text { nitroimidazoles }\end{array}$ & \multicolumn{2}{|l|}{ Desensitization } \\
\hline \multirow[t]{2}{*}{ Pregnancy } & Metronidazole & $\begin{array}{l}\text { - } 2 \text { g per os, single dose (avoid higher doses in } \\
\text { pregnancy) } \\
\text { - Consider multiple dose scheme if single dose } \\
\text { not tolerated [71] } \\
\text { - Treat all symptomatic cases } \\
\text { - If asymptomatic, consider treatment only in } \\
\text { the first trimester or after } 37 \text { weeks of } \\
\text { gestation }\end{array}$ \\
\hline & (Tinidazole) & $\begin{array}{l}\text { - Avoid in the first trimester } \\
\text { - Use in the second or third trimester only if no } \\
\text { better options available }\end{array}$ \\
\hline \multirow[t]{2}{*}{ Breastfeeding women } & Metronidazole & $\begin{array}{l}\text { - } 2 \text { g per os, single dose (discard milk for } \\
12-24 \mathrm{~h} \text { ) } \\
\text { - } 500 \mathrm{mg} 2 \text { id per os } 7 \text { days } \\
\text { - } 400 \mathrm{mg} 3 \text { id per os } 7 \text { days }\end{array}$ \\
\hline & (Tinidazole) & $\begin{array}{l}\text { - Avoid } \\
\text { - } 2 \text { g per os, single dose (discard milk for } 72 \mathrm{~h} \text { ) }\end{array}$ \\
\hline HIV patients & Metronidazole & - $500 \mathrm{mg} 2 \mathrm{id}$ for 7 days \\
\hline
\end{tabular}


Table 24.6 (continued)

\begin{tabular}{|c|c|c|}
\hline \multirow{3}{*}{$\begin{array}{l}\text { Alternative treatments in } \\
\text { resistant cases (always } \\
\text { consider non-compliance } \\
\text { or reinfection) }\end{array}$} & Metronidazole & $\begin{array}{l}-800 \mathrm{mg} 3 \text { id for 5-7 days } \\
\cdot 2 \mathrm{~g} \text { id for 5-7 days } \pm \text { intravaginal tinidazole }\end{array}$ \\
\hline & Tinidazole & $\begin{array}{l}\cdot 2 \mathrm{~g} \text { id per os for 5-7 days } \\
\cdot 2-3 \mathrm{~g} \text { id per os for } 14 \text { days (same for partners) }\end{array}$ \\
\hline & \multicolumn{2}{|c|}{$\begin{array}{l}\text { Options needing further studies: } \\
\text { - Zinc sulphate } 1 \% \text { ( } \pm \text { oral tinidazole) douches } \\
\text { - Pessaries (paromomycin/furazolidone/6\% non-oxynol-9) } \\
\text { - Boric acid (vaginal) } \\
\text { - Disulfiram } \\
\text { - Nithiamide } \\
\text { - Albendazole + nitroimidazole } \\
\text { - Coenzyme B12 + nitroimidazole }\end{array}$} \\
\hline
\end{tabular}

The rate of clinical cure can be improved by using sensitivity tests and tailoring the treatment according to it (higher doses of metronidazole or changing to tinidazole).

Topical metronidazole is not recommended for treatment, as it is associated with very low rates of cure $(<50 \%)$, probably due to the fact that only insufficient concentrations are achieved in the urethra and periurethral glands, which can act as reservoirs of the parasite. However, higher doses of vaginal metronidazole $(750 \mathrm{mg})$, combined with miconazole can lead to cure rates comparable to oral metronidazole [72].

It is still uncertain which is the impact of the coexistence of $\mathrm{BV}$ and $T$. vaginalis on the results of treatment, despite that both situations usually respond to nitroimidazole therapy [7].

Treatment during pregnancy, in one study increased the risk of preterm delivery three times (RR 3.0; 95\% confidence interval, 1.5-5.9) but this is still controversial and not confirmed in other studies [73, 74]. One of the theories sustains that the exposition of T. vaginalis infected with $M$. hominis to antibiotics leads to a massive release of the latter. These, once released, can infect the membranes and the amniotic fluid, thus initiating a preterm labour [73]. Treatment, however, reduces the risk of transmission to the newborn and decreases the risk of HIV infection. One reasonable option is treating all cases in the first trimester (to reduce HIV risk), the symptomatic cases at any time, and the asymptomatic ones after 37 weeks of gestational age (to reduce the risk of transmission, without increasing that of preterm labour) [53].

Women who test positive for $T$. vaginalis during pregnancy should be counselled to consistently use condoms, besides the adequate treatment of all sexual partners.

A test of cure can be performed 2-3 weeks after the treatment; prior to that, NAATs can be positive due to the presence of non-viable organisms. In pregnant women, given that $T$. vaginalis is a risk factor for HIV, the CDC recommends retesting after 3 months. In HIV women, retesting is also recommended [10].

\subsection{Dysbiosis}

\section{Vaginal Lactobacilli: Breaking the Myths}

- Bacterial vaginosis is not the only cause for absent lactobacilli in nonhypoestrogenic women. Aerobic vaginitis is another cause, which is much less recognized

- Despite the important role of Lactobacilli in vaginal health, they are absent in nearly one third of asymptomatic women

Vaginal dysbiosis refers to the conditions in which there is a flora disturbance or imbalance, characterized by a severe depletion or even absence of lactobacilli [75]. Traditionally, it has been assumed that BV is "the" cause for absent lactobacilli in non-hypoestrogenic women. However, clinical practice, especially with the use of WMM, has shown that it is not necessarily true. An increased $\mathrm{pH}$ (a marker of lactobacilli depletion and, thus, dysbiosis) is found not only in BV, but also in con- 
ditions in which aerobic, rather than anaerobic, bacteria predominate. Besides the overgrowth of aerobic bacteria, these women usually also have atrophy and inflammation (which are not part of BV) [76]. This entity was named aerobic vaginitis (AV) by Donders et al. in 2002 [77].

The non-recognition of AV may have led to serious drawbacks in clinical investigation, namely in the areas of preterm labour, sexually transmitted infections, and cervical dysplasia [78].

The concept of the essential role of the dominance of lactobacilli in the vaginal flora during reproductive age has been challenged, as it has been shown that it does not happen in nearly one third of asymptomatic women [79]. This is the rule in other species of mammals, in which lactobacilli represent only $1 \%$ of the vaginal microbiota, while one similar to that associated with BV dominates (Gardnerella, Mobiluncus, Sneathia, and Prevotella). Bacteriocins are not of exclusive production by lactobacilli; other bacteria such as Streptococcus, Prevotella, and Corynebacterium may fulfil that function [80].

\subsubsection{Bacterial Vaginosis}

Some authors have suggested that the condition should be named anaerobic vaginosis, rather than bacterial, as it overemphasizes a mere bacterial aetiology [81].

\section{Bacterial Vaginosis (BV): Breaking the Myths}

- BV may go unnoticed-it is asymptomatic in $50-85 \%$ of the cases

- $\mathrm{BV}$ is a sexually associated condition but not an STI, as no disease has been identified in the male partners, the condition cannot be attributed to a single microorganism, and treatment of the partner does not prevent recurrences in women.

\subsubsection{Aetiology and Pathophysiology}

$\mathrm{BV}$ is a polymicrobial syndrome, characterized by the absence of lactobacilli and overgrowth of a variable mixture of predominantly anaerobic and facultative bacteria, which in low loads are part of the normal vaginal flora. These can include G. vaginalis, Atopobium vaginalis, Mobiluncus, Prevotella, Megasphaera, Leptotrichia, Sneathia, Bifidobacterium, Dialister, Peptostreptococcus,

Fusobacterium, Clostridium, non-cultivable "BV-associated bacteria" (BVAB) 1-3, and $M$. hominis, among others, in loads 100-1000 times higher than the normal. Identifiable modifications in the microbiota precede the development of BV by weeks or months [82].

Given that these bacteria are sensitive to lactic acid and hydrogen peroxide, the initial step for the development of $\mathrm{BV}$ is likely to be the reduction or disappearance of lactobacilli. Several endogenous and exogenous factors, including phages and some Mollicutes, can be responsible for this [81, 83].

According to the model proposed by Nasioudis et al., it all starts with a transitory state of diminished lactobacillary dominance. During this stage, if the disturbing factor is enough to prevent the recovery of the lactobacilli or gives advantage to other bacteria in the competition for glycogen, a biofilm starts to be produced. The biofilm further deprives lactobacilli from having access to manganese, inhibiting their recovery, and allows the eviction of the already depressed innate immune system defences (low levels of $\mathrm{H}_{2} \mathrm{O}_{2}$ and lactic acid) [58, 84]. Additionally, the production of sialidase leads to the degradation of $\operatorname{IgA}$, impairing the acquired immune system response. The immunological response is typically absent or scarce $[58,84]$.

\subsubsection{Prevalence and Epidemiology}

$\mathrm{BV}$ is the most common cause of symptomatic vulvovaginal discharge in childbearing age women, accounting for nearly half of the cases. It is rarely encountered in children and becomes less common during menopause. Prevalence is lower during pregnancy [85].

As BV is asymptomatic in $50-85 \%$ of the cases, when comparing epidemiological data, it must be checked whether it refers to microbiological or clinical (symptomatic) disease and how the diagnosis was established. 
Global prevalence (symptomatic and asymptomatic) varies widely according to the population studied (12-55\%), being consistently higher in black women $(50-55 \%)$ [86, 87]. BV is much rarer in non-sexually experienced women, especially in those without any kind of sexual contact [88], but is very high $(20-50 \%)$ in women with female partners [89].

\subsubsection{Risk Factors and Associations}

BV is a sexually associated condition (Table 24.7). It cannot be considered an STI, as no disease has been identified in the male partners, the condition cannot be attributed to a single microorganism, and treatment of the partner does not prevent recurrences in women. However, there is a growing evidence that BVAB can be exchanged during intercourse, and it has been isolated from the penis, seminal fluid, and even urine of male partners of women with BV. The bladder may act as a reservoir for recurrences [90]. Circumcision can decrease the load of BVAB and, consequently the risk of $\mathrm{BV}$ in partners [91].

Table 24.7 Risk factors and associations for BV

\begin{tabular}{|c|c|}
\hline $\begin{array}{l}\text { Demographic } \\
\text { factors }\end{array}$ & $\begin{array}{l}\text { - Lower educational level } \\
\text { - Poverty } \\
\text { - Black race } \\
\text { - Childbearing age }\end{array}$ \\
\hline Sexual factors & $\begin{array}{l}\text { - New partner(s) } \\
\text { - Multiple partner(s) } \\
\text { - Higher number of lifetime sexual } \\
\text { partners } \\
\text { - Having female partner(s) } \\
\text { - Receptive oral sex } \\
\text { - Anal sex } \\
\text { - Higher frequency of intercourse } \\
\text { - Early sexual debut } \\
\text { - Unprotected sex } \\
\text { - Sharing sex toys }\end{array}$ \\
\hline $\begin{array}{l}\text { Behavioural } \\
\text { factor }\end{array}$ & $\begin{array}{l}\text { - Smoking } \\
\text { - Vaginal douching } \\
\text { - IUD } \\
\text { - Not using oral contraceptives } \\
\text { - Having an STI (HIV, HSV2, C. } \\
\text { trachomatis, M. genitalium) } \\
\text { - Uncircumcised partner } \\
\text { - Antibiotic use } \\
\text { - Stress } \\
\text { - Dietary factors (increased fat, low } \\
\text { calcium, folate, and vitamin A) }\end{array}$ \\
\hline
\end{tabular}

While women usually do not consider it an STI themselves, they can link sexual activity to the development or recurrence of symptoms [92].

Phages can be the "missing link" between BV and its association with sexual activity: hypothetically, a partner may transmit it, leading to the depletion of lactobacilli [81]. Interestingly, phages are promoted by smoking, which is also a risk factor for $\mathrm{BV}$, by direct toxicity to lactobacilli, and by inducing hormonal changes [93].

While $L$. crispatus is associated with a lower risk for $\mathrm{BV}, L$. iners can be identified during dysbiosis. It is uncertain whether it predisposes to dysbiosis or is part of the recovery process [82, 94]. Interestingly, female couples share lactobacilli strains [95].

Progesterone seems to play a protective role, as the rates of $\mathrm{BV}$ are lower and the cure rates higher during pregnancy, and less cases are detected during the luteal phase [96].

\subsubsection{Signs and Symptoms}

More than half of the women with BV type flora are asymptomatic. If not, symptoms tend to be mild, fluctuating and sometimes with a longstanding duration (weeks or months).

The most common symptom is an offensive fishy smell, which typically worsens with menses and sexual intercourse, as the release of volatile amines (putrescine and cadaverine) is increased in elevated $\mathrm{pH}$. Sometimes women tend to wash more frequently or to use perfumed products, which paradoxically further worsen the smell.

The discharge associated with BV is yellow or grey, homogeneous, thin, and adherent to the vaginal walls (Fig. 24.13a). Mild burning or dysuria are sometimes described, but are not typical features of BV.

The vulvar and vaginal exam, apart from the presence of discharge, are usually unremarkable (Fig. 24.13b).

$\mathrm{BV}$ can be considered recurrent if a woman has 3 or more episodes during 1 year.

\subsubsection{Complications}

The risk of complications is independent of whether or not a woman is symptomatic. 

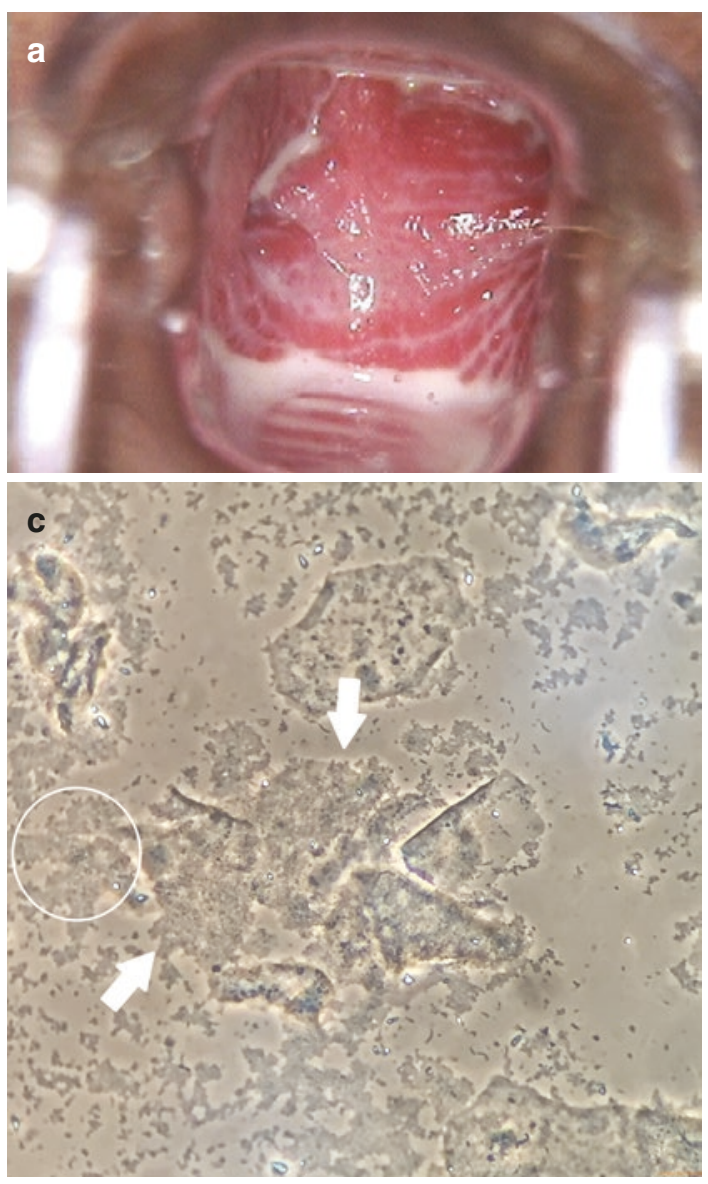

Fig. 24.13 (a) Homogenous vaginal discharge in a woman with bacterial vaginosis. (b) At the vulva, the homogenous vaginal discharge can be easily detected in women with bacterial vaginosis. (c) Bacterial vagi-

Most studies failed to distinguish BV from $\mathrm{AV}$, as the diagnosis was frequently based on an increased $\mathrm{pH}$ and/or absence of lactobacilli. This can explain different results between studies and why, for instance, treatment failed to reduce the risk of preterm labour in women with the diagnosis of BV. The listed complications most likely represent those of abnormal vaginal flora or dysbiosis, rather than just of BV.

BV was first associated with adverse pregnancy outcomes in 1984, namely with preterm labour. Following that, other obstetrical and neonatal complications were added to the list: spontaneous abortion, low birth weight and increased neonatal morbidity [97].

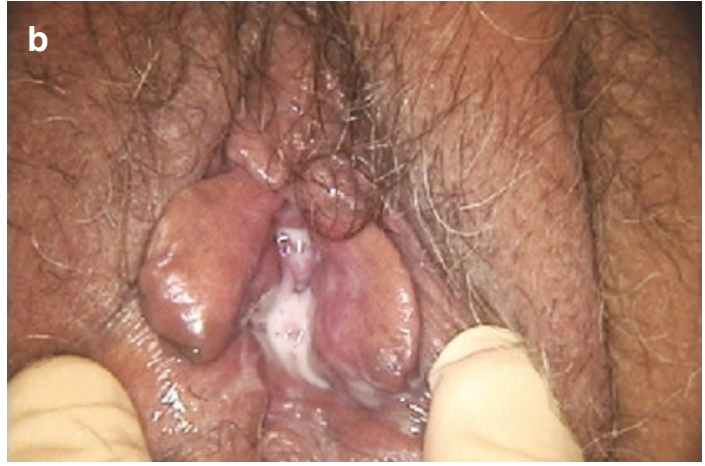

nosis with all typical features: no lactobacilli, granular floor (white circle) and clue cells (white arrows) (phase contrast, 400×)

Pelvic inflammatory disease, posthysterectomy cuff infection and post C-section endometritis are also more common in women with BV. Interestingly, there are theories sustaining that one of the roles of vaginal lactobacilli may be the reduction of the infectious risks related to pregnancy and delivery [80].

The risk of acquiring an STI, including $C$. trachomatis, $N$. gonorrhoea, HSV2 and HIV infection, is double in women with BV [98]. $U$. urealyticum, $U$. parvum and $M$. hominis, but not M. genitalium, are frequently found associated with BV [99].

Additionally, it increases the risk of transmission of HIV to male partners [100]. Several 
studies link BV to HPV persistence, cervical dysplasia and cancer.

More recently, there is increasing data relating BV with infertility and lower success rates of assisted reproduction techniques [101].

\subsubsection{Diagnosis}

BV should not be screened in asymptomatic women; it can be considered, but without enough evidence to recommend it, in pregnant women, prior to pelvic surgery or uterine cavity instrumentation, or in those with STIs, especially HIV.

\section{Clinical Diagnosis}

Clinical criteria allow the diagnosis of BV in settings of limited resources or expertise. To fulfil the Amsel criteria [102], 3 out of the following 4 must be fulfilled:

1. Homogeneous grey or white discharge coating the vaginal walls (Fig. 24.13a, b);

2. Vaginal $\mathrm{pH}$ increased $(>4.5)$;

3 . Fishy smell (before or after $10 \% \mathrm{KOH}$ addition-Whiff test);

4. Clue cells on wet mount (cells with a heavy coating of bacteria, leading to blurring of the peripheral borders; must be present in $>20 \%$ of cells) (Fig. 24.13c).

The sensitivity and specificity of the Amsel criteria is around 80 and $90 \%$, respectively. The first three criteria are also frequently positive in women with trichomoniasis. The combination of only $\mathrm{pH}$ and Whiff test may perform better than the traditional criteria [103]. However, odour is too subjective to base a diagnosis on; in the future, it may be overcome by the use of "electronic noses" [104].

In our opinion, in settings where a microscope is available, it should be used for the proper diagnosis of BV by WMM, rather than just for the mere evaluation of the presence of clue cells.

\section{pH}

The $\mathrm{pH}$ based point of care tests available for self-testing have a sensitivity and specificity of $73 \%$ and $67 \%$, respectively [105].
The VI-SENSE is a pH test, based on a strip placed in a panty liner; clinical trials showed good performance for BV or trichomoniasis, but not allowing distinction between both conditions [106].

\section{Microscopy}

In WMM, BV is characterized by absent lactobacilli, granular flora or abundant motile small, curved, rod shaped bacteria (Mobiluncus), absence of inflammation, and presence of clue cells (Fig. 24.13c).

WMM has several advantages relatively to Gram staining based Nugent score: (1) it is cheaper, (2) allows the diagnosis during the appointment, (3) requires less expertise, (4) allows the distinction of full-blown from partial $\mathrm{BV}$ (in which in the same slide areas of granular flora can coexist with areas with lactobacilli, and frequently clue cells represent $<20 \%$ of the total number of epithelial cells) and the overcome of the problem of "intermediate scores" from Nugent score, and (5) the evaluation of the bacteria may be more accurate, since there is no fixation and washing of the slides.

The Nugent score, an improvement from the Spiegel score, was described in 1991 [107], and is considered the gold standard for the diagnosis of BV. It is based on the proportion of bacterial morphotypes, using Gram staining:

- Lactobacilli (large Gram-positive rods) - 0 to 4 points (higher scores if less abundant);

- G. vaginalis and bacteroides (small Gram variable rods) -0 to 4 points (higher scores if more abundant;

- Mobiluncus-like morphotypes (curved Gram negative rods) -0 to 2 points (higher scores if more abundant);

- (Gram-positive cocci are not considered in this scoring system).

The diagnosis of BV is established if the final score is equal or higher than seven. If it is equal or lower than three, it is considered normal. A score between 4 and 6 is the troublesome "intermediate score". It does not correspond to partial $\mathrm{BV}$; part of the cases classified in this grey area, 
which usually do not respond to metronidazole treatment, may represent AV. For this reason, Donders proposed that "undetermined flora" would be a more accurate description [108].

The Hay and Ison criteria [109], also based on Gram staining may allow a more complete and realistic evaluation of the vaginal flora:

- Grade 0-epithelial cells with no bacteria seen;

- Grade I-lactobacillus morphotypes only (normal flora);

- Grade II-reduced lactobacillus morphotypes with mixed bacterial morphotypes (intermediate flora);

- Grade III-mixed bacterial morphotypes with few or absent lactobacillus morphotypes (BV);

- Grade IV-epithelial cells covered with Gram-positive cocci only (AV type flora).

\section{Cultures}

G. vaginalis can be cultivated from the large majority of women with $\mathrm{BV}$, but also from more than half of the women without it [110]. This translates into a high sensitivity, but a low positive predictive value and thus should not be used.

\section{Pap Test}

The Pap test is not intended for the diagnosis of vaginitis. The sensitivity for BV is low, and likely to be even lower when using liquid based cytology, due to centrifugation and filtering of the sample.

\section{Enzymatic Tests}

The OSOM BVBlue is a point of care test, based on the chromogenic determination of the presence of sialidase, which is produced by bacteria commonly involved in BV (Gardnerella, Prevotella and Bacteroides). The results are available within $10 \mathrm{~min}$. The sensitivity of the test is variable (38$100 \%$ ), while the specificity is systematically high $(>90 \%)$ [111]. In AV, sialidase is also increased and it may explain part of the differences in sensitivity across studies.

Tests to evaluate the activity of proline aminopeptidase have also been designed, giving the results in $10 \mathrm{~min}$. Sensitivity and specificity are higher than $90 \%$ [112]. It has also been evaluated in combination with $\mathrm{pH}$ and amines determination (FemExam).

\section{Molecular Tests}

The use of DNA tests in BV is very complex, as it is polymicrobial and most of the involved agents commonly colonize the vagina of healthy women in low loads. These techniques are usually highly sensitive, but with low predictive positive values. In the future, combinations of evaluation of the proportion of selected anaerobic bacteria and lactobacilli may increase the specificity of this methodology [113].

Nevertheless, the Affirm VPIII, which tests not only BV, but also T. vaginalis and Candida, has been shown to be a good alternative in settings where a microscope is not available [25, 26].

\subsubsection{Treatment}

BV can heal spontaneously [53]. Treatment aims at resolving the symptoms associated with $\mathrm{BV}$; there is no indication to treat asymptomatic women. It can, however, be considered in highrisk populations for STIs, as it can reduce the risk of acquiring HIV, T. vaginalis, C. trachomatis, $N$. gonorrhoea and HSV2, and before pelvic surgery.

Therapeutic options for BV include oral and topical antibiotics (metronidazole, tinidazole and clindamycin), and antiseptics (dequalinium chloride) (Table 24.8). The rates of cure are high for all drugs and routes (around 80\%), but relapses are common [10, 114].

The vaginal levels achieved with topical medication can be 30 times higher than those achieved with oral medication. This translates into cure rates equal or slightly higher than those achieved with the oral route, with the advantage of having less adverse effects. Combinations of oral and vaginal treatment can increase the cure rates [115].

Despite the perceived increased resistance to metronidazole and clindamycin, it does not seem yet to be a major clinical issue $[85,116]$. Some Gardnerella strains have been shown to be intrinsically resistant to metronidazole [117]. Several of the bacteria involved in BV cannot be cultivated, thus making it impossible to test its susceptibility profiles.

The cure rates achieved with the antiseptic dequalinium chloride are non-inferior to those of clindamycin [116]. It has the advantages of being less toxic for lactobacilli, and not increasing the risk of VVC, contrarily to antibiotics [118]. 
Table 24.8 Treatment of BV

\begin{tabular}{|c|c|c|}
\hline \multirow[t]{4}{*}{ First line } & Metronidazole tablets & $500 \mathrm{mg}$ per os 2 id 7 days \\
\hline & Metronidazole gel $0.75 \%$ & $5 \mathrm{~g}$ id intravaginally 5 days \\
\hline & Clindamycin cream $2 \%$ & $5 \mathrm{~g}$ id intravaginally 7 days \\
\hline & Dequalinium chloride & $10 \mathrm{mg}$ tablets $i d$ intravaginally 6 days \\
\hline \multirow[t]{4}{*}{ Second line } & Tinidazole & $2 \mathrm{~g}$ id 2 days \\
\hline & Tinidazole & $1 \mathrm{~g}$ id 5 days \\
\hline & Clindamycin & $300 \mathrm{mg}$ per os 2 id 7 days \\
\hline & Clindamycin & $100 \mathrm{mg}$ vaginal ovules $i d$ for 3 days \\
\hline \multirow{4}{*}{ Alternatives } & Secnidazole & 2 g per os, single dose \\
\hline & $\begin{array}{l}\text { Polyhexamethylene biguanide } \\
\text { hydrochloride }\end{array}$ & $1-2$ id for 7 days \\
\hline & Chlorhexidine & Vaginal douche once a day \\
\hline & Rifaximin & $25-100 \mathrm{mg}$ id intravaginally \\
\hline \multirow{4}{*}{$\begin{array}{l}\text { Recurrent } \\
\text { BV }\end{array}$} & Metronidazole $0.75 \%$ gel & 2 times/week for $4-6$ months \\
\hline & $\begin{array}{l}\text { Triple phase regimen: Oral } \\
\text { nitroimidazole, vaginal boric acid, } \\
\text { and vaginal metronidazole }\end{array}$ & $\begin{array}{l}\text { - Oral nitroimidazole for } 7 \text { days } \\
\text { - Vaginal boric acid for } 3 \text { weeks } \\
\text { - Vaginal metronidazole gel twice a week for } 16 \text { weeks }\end{array}$ \\
\hline & $\begin{array}{l}\text { Metronidazole } 2 \mathrm{~g}+\text { fluconazole } \\
150 \mathrm{mg}\end{array}$ & Once a month \\
\hline & Ascorbic acid & $250 \mathrm{mg}$ vaginal tablets id 6 days/month for 6 months \\
\hline
\end{tabular}

Additionally, it is not expected that bacteria develop resistance to it and can have some effect in other causes of "vaginitis" other than BV, thus making it at least partially useful for mixed infections, including AV, VVC and trichomoniasis [116]. However, long-term studies concerning recurrences are still lacking.

Women must be warned about the possible interaction between alcohol and nitroimidazoles. Clindamycin is associated with pseudomembranous colitis, and topical formulations may weaken latex condoms.

The use of $\mathrm{H}_{2} \mathrm{O}_{2}$ irrigations has resulted in contradictory results, but it seems to be less effective than metronidazole, and associated with a risk of development of severe lesions in the vaginal mucosa, due to its caustic effects [119].

The use of acidifying agents, though tempting, has not proven to be efficacious. Only the use of ascorbic acid has some clinical support [120].

There is no evidence that the use of probiotics in acute episodes, isolated or concomitantly with antibiotics improves the rate of success [121].

\section{Pregnancy}

Treatment of BV during pregnancy with metronidazole failed to decrease the risk of preterm labour and, in some studies, even lead to an increase. On the contrary, in most series in which clindamycin was used showed a decrease in the rate of preterm labour [122-124]. Difference in terms of outcomes may be related to the antibiotics spectrum: clindamycin covers Gram-positive bacteria, frequently involved in AV. New studies with a more accurate classification of the vaginal flora may settle the question in the near future.

While treatment of symptomatic women during pregnancy is recommended, the available data does not allow the recommendation of screening and treating asymptomatic cases.

All first line schemes recommended for nonpregnant women can safely be used during all trimesters of pregnancy. There was some concern about the use of clindamycin during the second half of pregnancy, but it has been shown that there is no reason for that $[10,53,125]$.

\section{Recurrent BV}

Antibiotic treatment is usually effective, but relapses are common, estimated at $50-70 \%$ at 6-12 months [126]. There is contradictory data associating A. vaginae and specific strains of $G$. vaginalis with failure of treatment and recurrences $[85,127,128]$. Bacterial strains that produce more sialidase have a higher potential of developing a biofilm and adhering to epithelial cells [129]. 
Higher loads of bacteria also seem to correlate with an increased risk of recurrence [130].

Recurrent episodes can be managed by using a different antibiotic/antiseptic from the previous episode, for a longer duration. The use of repeated options in the subsequent episodes is an acceptable approach [131].

Some patients will opt for a suppressive treatment. The use of metronidazole $0.75 \%$ gel twice a week for 4-6 months is one of the most commonly used regimens, with an efficacy of $70 \%$. However, the rate of relapse severely increases once it is stopped and VVC is not uncommon during treatment (43.1\%) [132]. A regimen in which $2 \mathrm{~g}$ of oral metronidazole and $150 \mathrm{mg}$ of oral fluconazole monthly was used, in HIV1 women showed to be effective, and the risk of VVC was lower than in the placebo arm [133].

There is no advantage in the treatment of male partners, however this recommendation is not based on good quality studies [10, 134]. If the phages theory proves to be correct, the male treatment will not be effective indeed.

Using oral contraceptives continuously for 3 months is a strategy that can be tried; it may work both by reducing the levels of oestrogens and by eliminating the exposure to blood [85].

A triple sequential scheme, including oral metronidazole or tinidazole, vaginal boric acid, and vaginal metronidazole, has shown a cure rate of $65 \%$ at 28 weeks, but it has a failure rate of $50 \%$ at 36 weeks [135].

Recurrences/treatment failures seem to be associated with inability to eradicate the biofilm. Boric acid is one of the agents capable of destroying it; other options may include tobramycin, DNases, octenidine, and retrocyclin, among others [98].

The concept of using probiotics to restore the vaginal health is intuitive and appealing, however the studies have not supported its use. It does not seem to affect the cure rate, but may increase the time to recurrence in $50 \%$ [136, 137]. Failure to improve the vaginal flora with probiotics may be due to the use of inadequate species (the ones commercially available usually are not dominant ones in healthy women) and/or inability to colonize the vagina.
There is no data supporting the use of acidifiers of the vagina for the purpose of avoiding recurrences [138].

Future options may include oral or vaginal lactoferrin, which can act by immunomodulation, disruption of the cell membranes, and by binding to iron and thus making it unavailable for bacteria (without affecting lactobacilli, which rely on manganese for their metabolism) [126].

\subsubsection{Aerobic Vaginitis, Desquamative Inflammatory Vaginitis, GBS Vaginitis}

\section{Aerobic Vaginitis: Breaking the Myth}

- Group B streptococcus (GBS) infection and desquamative inflammatory vaginitis (DIV) are not separate entities. They are a part of aerobic vaginitis (AV).

In 2002, Donders et al. named a condition characterized by lack of lactobacilli, presence of aerobic (enteric) bacteria, and atrophy as aerobic vaginitis, thus stressing the main differences between this entity and its anaerobic, non-inflammatory, counterpart: BV [77]. Its most severe forms of presentation correspond to the desquamative inflammatory vaginitis (DIV), described by Gardner in 1968 [139] (probably the same as Scheffey's "exudative vaginitis" [140]). While DIV is an extreme form of the disease, AV shows the full spectrum of the disease [141].

Group B streptococcus (GBS) vaginitis is also included in the spectrum of AV. GBS is today considered one of the agents commonly found in women with AV.

Even though it is more and more recognized as a nosologic entity, unfortunately it still is not the rule. Failure to recognize it may be a missed opportunity to help women with otherwise "untreatable" or "unspecific" vaginitis, and to diminish the associated gynaecological and obstetrical risks associated with it.

As we consider these entities as subtypes of $\mathrm{AV}, \mathrm{AV}$ will be used to discuss it as a whole. 


\subsubsection{Aetiology}

The aetiology of AV remains unknown. Although the isolation of bacteria other than lactobacilli is one of the features of $\mathrm{AV}$, it cannot be assumed straightforward that AV is an infection-its presence may be secondary to the abnormal local conditions. The most commonly isolated bacteria are Streptococcus spp., S. aureus, coagulase negative staphylococci, E. coli and E. faecalis [142].

The lack of lactobacilli, namely the $\mathrm{H}_{2} \mathrm{O}_{2}$ producing strains which are capable of reducing the levels of IL-1 $\beta$ [143] can, partially, explain the inflammatory response found in AV.

Host immunity factors can also be involved, as not only the levels of IL-1 $\beta$ are increased (higher than in women with BV), but also those of IL-6 and -8 (while in BV they are within normal range) [144, 145]. Sialidase, which leads to diminished local immunity by ultimately causing $\operatorname{Ig}$ A proteolysis, is increased in both $\mathrm{AV}$ and BV [144].

The presence of intermediate or even parabasal cells suggests a role for hypoestrogenism. However, it must be a local phenomenon, given that it can be seen in women without further evidence of low oestrogens, and systemic treatment is ineffective.

Other theories include that AV/DIV might be localized forms of lichen planus, or that it is a consequence of low levels of vitamin D [142].

\subsubsection{Prevalence and Epidemiology}

Data concerning the epidemiology of $\mathrm{AV}$ is still scarce, however we are starting to see the broad picture. Comparing data on prevalence is not easy, as studies considered different grades of $\mathrm{AV}$, some looked only into symptomatic women, and others considered only pregnant women.

In Europe, the prevalence rate of moderate or severe AV (msAV) seems to range between 7.4 and $12.0 \%$, while it seems to be less common in South America (2.0-2.9\%), and more common in Africa (11.0-25.8\%) [142]. The prevalence is systematically lower in pregnant women (4.0-8.0\%) [57], and in one study it has been shown to be very high in a cohort of 123 HIV positive women $(26.8 \%$ with msAV and $20.4 \%$ with light forms) [146].

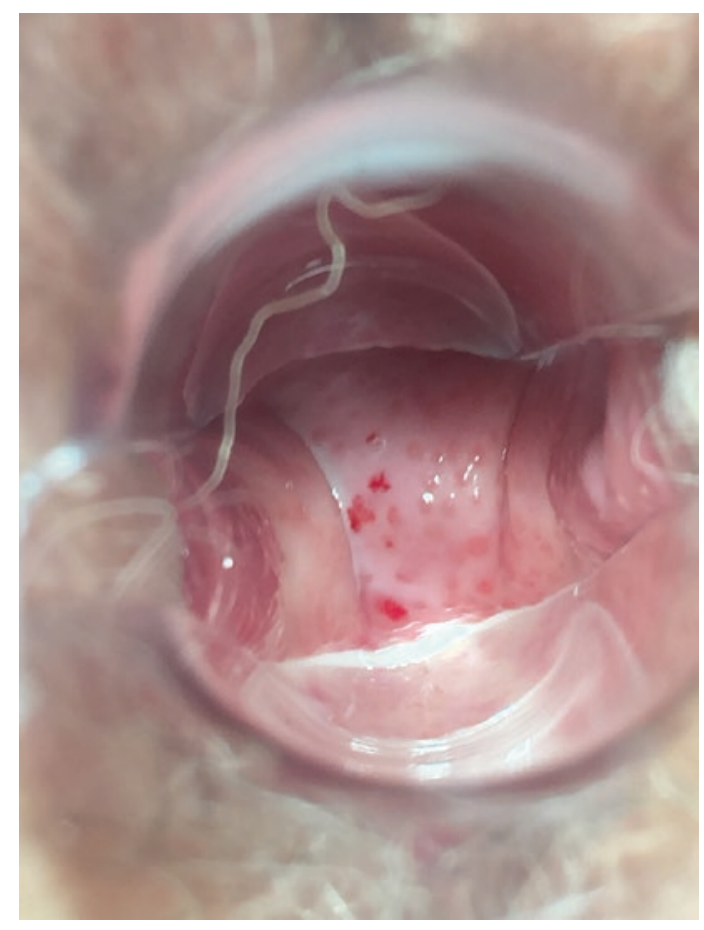

Fig. 24.14 Erosions of the vaginal walls in a patient with severe aerobic vaginosis

It can be found in women of all ages (not studied in children), but there seems to exist a peak in the peri-menopausal period.

\subsubsection{Risk Factors and Associations}

Up to the moment, the studies concerning risk factors and associations with AV are very limited. One Chinese study associated AV with being unmarried, using an IUD, long-term use of antibiotics, and vaginal douching; on the contrary, higher education and systematic use of condoms were protective [147]. The latter was not confirmed in a European study [78].

\subsubsection{Signs and Symptoms}

AV can range from asymptomatic to highly symptomatic. Symptoms can include yellowish or yellow-green vaginal purulent discharge (in 20\% with a rotten smell-different from the fishy one typical of BV), dyspareunia, burning and stinging. The vagina and the vestibule can be reddish and with erosions (Fig. 24.14) [57, 77]. Symptoms can be present for months with variable intensity [142]. 


\subsubsection{Complications}

The number of studies linking AV with severe gynaecological and obstetrical complications has been growing the last years [142].

Among gynaecological complications, there are studies relating it to an increased risk of having an abnormal Pap test and of acquiring STIs. The presence of inflammation and erosions, the lack of lactobacilli, and the associated increased levels of sialidase can easily explain the increased risk for STIs; diagnosing and treating AV can be highly relevant in populations at elevated risk, namely in Africa [87, 118].

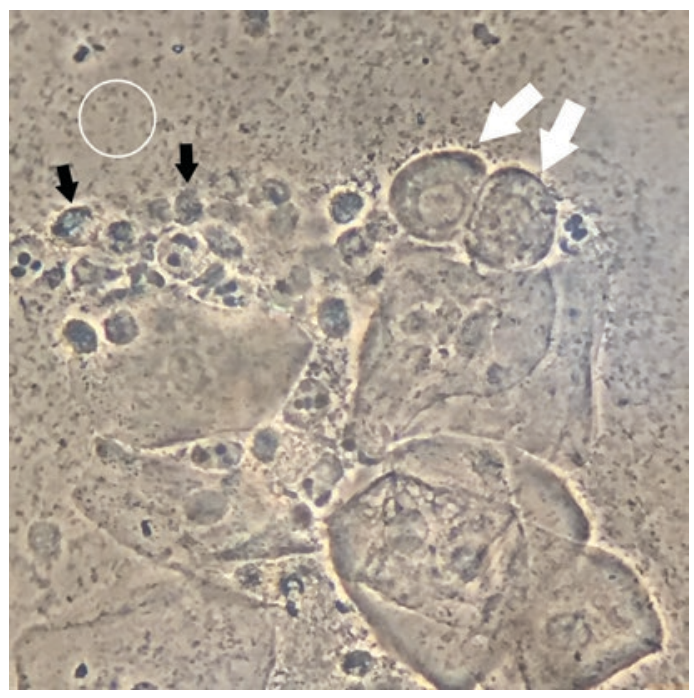

Fig. 24.15 Severe aerobic vaginosis/desquamative inflammatory vaginitis: absent lactobacilli, basal/parabasal cells (white arrows), cocci (white circle), and inflammation (black arrows) (phase contrast 400×)
In terms of obstetrics, it can be the explanation for the contradictory results found when relating flora changes to preterm labour. It has also been linked to premature rupture of membranes, chorioamnionitis and even neonatal sepsis.

The interleukin profile associated with these complications, as well as that associated with cervical intraepithelial neoplasia and cervical cancer are near perfect matches with that of $\mathrm{AV}$ $[78,142,148]$.

\subsubsection{Diagnosis}

The diagnosis of AV is made with the aid of a microscope, ideally with phase contrast (Fig. 24.15). A composite score must be calculated, including: (1) relative quantity of lactobacilli; (2) presence of inflammation; (3) relative quantity of toxic leucocytes (active, swollen leucocytes); (4) presence of other bacteria and (5) proportion of parabasal cells (Table 24.9). WMM is a better tool than Gram staining, as the former allows a more precise evaluation of the lactobacillary grades.

Cultures are not useful, as it is not informative of the relative proportion of lactobacilli and other bacteria and colonization is common [113].

The $\mathrm{pH}$ is usually increased, in a more pronounced way than in BV [149].

Rumyantseva et al. have shown that molecular diagnosis, using real time PCR is feasible and, in the future, can be an option in settings where health care professionals are not trained to perform microscopy [113]. Enzymatic test has already been developed, but validation is still needed [150].

Table 24.9 AV score

\begin{tabular}{l|l|l|l|l|l}
\hline Score & Lactobacillary grade & $\begin{array}{l}\text { Inflammation } \\
\text { (leucocytes) }\end{array}$ & Toxic leucocytes & $\begin{array}{l}\text { Presence of other } \\
\text { bacteria }\end{array}$ & $\begin{array}{l}\text { Proportion of } \\
\text { parabasal cells }\end{array}$ \\
\hline 0 & I or IIa & $\leq 10$ per HPF & Absent & $\begin{array}{l}\text { Unremarkable or } \\
\text { cytolysis }\end{array}$ & $<1 \%$ \\
\hline 1 & IIb & $\begin{array}{l}>10 \text { per HPFand } \\
\leq 10 \text { per cell }\end{array}$ & $\leq 50 \%$ & $\begin{array}{l}\text { Small coliform } \\
\text { bacilli }\end{array}$ & $1-10 \%$ \\
\hline 2 & III & $>10$ per cell & $>50 \%$ & $\begin{array}{l}\text { Cocci or chains of } \\
\text { cocci }\end{array}$ & $>10 \%$ \\
\hline
\end{tabular}

Score $<3$-no AV; score 3 to 4-light AV; score 5 to 6-moderate AV; score $>6$ - severe AV. Lactobacillary grades: I—only numerous pleomorphic lactobacilli; IIa—dominance of lactobacilli, but other bacteria present; IIb—dominance of other bacteria, but still some lactobacilli present; III-lactobacilli absent or severely depressed and dominance of other bacteria. Use 400× magnification. $H P F$ high power field. Adapted from Donders et al. [145] 
Table 24.10 Treatment of Aerobic Vaginosis. Donders et al. [142]

\begin{tabular}{|c|c|c|}
\hline \multirow[t]{3}{*}{ Antiseptics } & Dequalinium chloride & $i d$ for 6 days \\
\hline & Iodopovidone & \multirow{2}{*}{$\begin{array}{l}\text { (Transient effect, low impact on } \\
\text { lactobacilli, washing effect?) }\end{array}$} \\
\hline & Chlorhexidine & \\
\hline \multirow[t]{2}{*}{ Topical antibiotics } & Clindamycin cream $2 \%$ & $i d$ for 2 weeks \\
\hline & Rifaximin $25-100 \mathrm{mg}$ & $i d$ for 6 days \\
\hline Systemic antibiotics & Moxifloxacin $400 \mathrm{mg}$ & $\begin{array}{l}\text { id for } 6 \text { days (repeat if absence of } \\
\text { microscopic cure) }\end{array}$ \\
\hline Topical steroids & Hydrocortisone cream $10 \%$ & $\begin{array}{l}3-5 \text { times/week (vaginal) } \\
\text { advisable to concomitantly use } \\
\text { antifungals? }\end{array}$ \\
\hline Topical oestrogens & $\begin{array}{l}\text { Estriol } \\
\text { Estradiol }\end{array}$ & According to usual schemes \\
\hline Probiotics & L. acidophilus + estriol $30 \mu \mathrm{g}$ & id for 6-12 days \\
\hline Other & Nifuratel $500 \mathrm{mg}$ & id 10 days (topical or oral) \\
\hline
\end{tabular}

\subsubsection{Treatment}

Treatment of AV is not yet standardized and further studies are needed in this specific field. The treatment is guided by the microscopy findings: It must be attempted to correct the atrophy (topical oestrogens), the inflammation (topical steroids) and the presence of bacteria (antiseptics, topical and antibiotic antiseptics). In one study, probiotics have shown to increase the time to recurrence [136] (Table 24.10).

If antibiotics are chosen, preference should be given to topical formulations, to those active against Gram negative bacilli and Gram-positive cocci, and as innocuous as possible to lactobacilli. The use of the antiseptic dequalinium chloride was less associated with Candida at the end of the treatment, when compared to antibiotics [118].

\subsection{Cytolytic Vaginosis, Lactobacillosis and "Leptothrix"}

\section{Cytolytic Vaginosis: Breaking the Myths}

- Lactobacilli are not always protectiveIncrease in lactobacilli may cause cytolytic vaginosis, a special form of sometimes symptomatic vaginal discharge

- Cytolytic vaginosis symptoms closely mimic those of vulvovaginal candidiasis
The dominance of the vaginal milieu by lactobacilli species and the consequent low $\mathrm{pH}$ is unique to the human species. Its main goal seems to be the protection against sexually transmitted infections (STIs) and, ultimately, the consequences of it in the offspring. In evolutionary terms, it may have happened as a consequence of the continuous ovarian cycle (and, consequently, an increased risk of exposure to STIs, when compared to other species) or due to the high consumption of starch, which occurred after the agricultural revolution [80, 151]. Other authors have highlighted the need for a protective environment during delivery, as due to the disproportion between the head and the pelvis, the likelihood of vaginal wall lacerations is higher than in other species. However, this unique situation can turn against the host [80].

Higher levels of oestrogens, as seen just before ovulation, are directly linked to the lactobacilli abundance, lower vaginal $\mathrm{pH}$, thickening of the vaginal epithelium, and increased production of glycogen [80].

For still unknown reasons, sometimes the lactobacilli can be a cause of cytolysis (cytolytic vaginosis $[\mathrm{CV}]$ ), can be increased in number (lactobacillosis), or longer than normal (previously denominated "leptothrix"). These are controversial entities, and it is still unknown whether or not they are part of the same spectrum. Some authors consider lactobacillosis and "leptothrix" as one single entity.

These are not infectious causes of "vaginitis", but are important differential diagnosis of VVC, 
which are commonly found in women with suspected "resistant" or recurrent candidiasis.

\subsubsection{Cytolytic Vaginosis}

\subsubsection{Aetiology}

It has not been fully understood what leads to the overgrowth of lactobacilli in some women or why does it lead to the destruction of the intermediate cells of the vaginal epithelium. It is highly likely that hormones play a role in the development of $\mathrm{CV}$, as it is more common-or more symptomatic, during the luteal phase, pregnancy or perimenopause [152].

The cytolysis may be the consequence of the very low $\mathrm{pH}$, due to the increased degradation of glycogen by the large number of lactobacilli.

Lactobacilli, except for $L$. iners, produce both $\mathrm{L}$ - and D-lactic acid (L. iners produces only the L-isomer); vaginal cells produce only the Lisomer. An imbalance in the local ratio between the two isomers, in favour of the L-isomer, can be involved in the development of $\mathrm{VC}$, by altering the expression of the extracellular matrix metalloproteinase inducer [153].

Most women with symptomatic CV were previously treated with repeated courses of antifungals, which lead some authors to try to establish an association. However, this association is more likely to be due to the fact that they were previously misdiagnosed as Candida and thus treated as so.

\subsubsection{Prevalence and Epidemiology}

The prevalence of $\mathrm{CV}$ in asymptomatic women ranges between 1 and $7 \%$, peaking during the reproductive years [152]. Despite the now acknowledged racial differences in terms of vaginal microbiome composition, it is not known if it has any impact in the prevalence of $\mathrm{CV}$.

\subsubsection{Risk Factors and Associations}

One study suggested that less sexually active women were more likely to have $\mathrm{CV}$, but it can be biased, as the comparison group was with sexual workers [154]. It has been suggested, also in one isolated study, that women with $\mathrm{CV}$ are less likely to have an abnormal Pap test, but we could not confirm it [155].

\subsubsection{Signs and Symptoms}

VC mimics the symptoms of VVC; almost all patients were previously treated with antifungals, either for a suspected diagnosis performed by a physician or by self-diagnosis.

The clinical history most of the times is enough to raise a high level of suspicion for CV.

The most striking symptom is burning, rather than pruritus. The typical discharge is white, sometimes lumpy and abundant (Fig. 24.16); some women will describe that it smells like vinegar. Dysuria and dyspareunia may also be among the list of symptoms. Symptoms tend be cyclic, aggravating in the luteal phase, peaking just before the menses. There is usually a great relief associated with menstruation or withdrawal bleeding. It is common that women report a transitory relief with the use of topical antifungals, but not oral formulations, probably due to a buffering effect.

The vulvar exam may be unremarkable, or some degree of erythema and/or oedema can be present. Fissures are an uncommon feature.

\subsubsection{Complications}

The very few studies about CV usually did not address the issue of complications. In one single study, we found that $\mathrm{CV}$ is much more prevalent

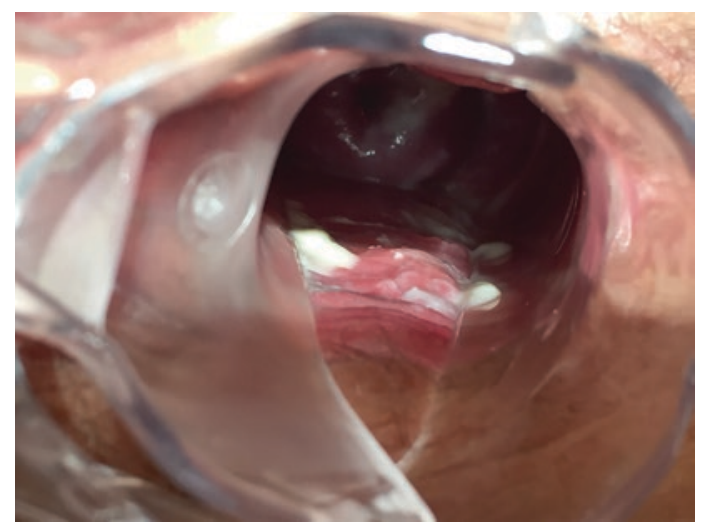

Fig. 24.16 Abundant, lumpy discharge in a woman with cytolytic vaginosis 
in women with localized provoked vulvodynia, when compared to healthy controls $(16.5 \%$ vs. $4.1 \%, p=0.000)$ [156]. However, women with vulvodynia tend to have less frequent intercourse and, as referred before, $\mathrm{CV}$ has been found to be more common in less sexually active women [154]. On the other side, there is a biological plausibility that the chronic exposure of the vestibule to a very low $\mathrm{pH}$, excessive amounts of $\mathrm{H}_{2} \mathrm{O}_{2}$, or the association to a specific lactobacillus species can be involved in the development of some cases of vulvodynia. Ventolini et al. associated L. gasseri with vulvodynia, which can lead to the speculation that this can be a common link between the two entities [157].

\subsubsection{Diagnosis}

The diagnosis is made using the microscope (Table 24.12). It is characterized by the presence of an abundant number of lactobacilli, bare nuclei and cellular debris (in extreme cases, no intact cells are seen in the slide). Inflammation, clue cells, bacteria other than lactobacilli, and T. vaginalis are typically absent (Fig. 24.17). Although, per definition, the diagnosis implies the exclusion of the presence of Candida, given the typically low $\mathrm{pH}(<4.0-4.2)$ the coexistence of both is not rare.

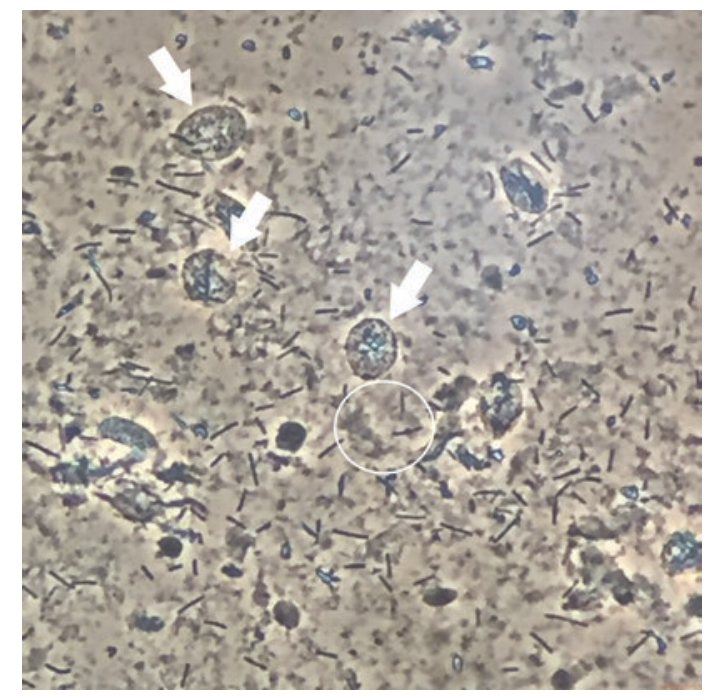

Fig. 24.17 Cytolytic vaginosis. Bare nuclei (white arrows), cellular debris (white arrows) and abundant lactobacilli
Cultures for fungi can be used to exclude the presence of Candida.

\subsubsection{Treatment}

The treatment consists of increasing the $\mathrm{pH}$ of the vagina (buffer effect), which will diminish the load of lactobacilli in the vagina and ameliorate the symptoms.

Vaginal irrigations with sodium bicarbonate are highly effective in controlling the symptoms. While some authors recommend sitz baths, in our experience irrigations are much more effective (Table 24.11). In recurrent cases, if a pattern is identified, treatment should be started 24-48 $\mathrm{h}$ prior to the anticipated moment of onset [159].

\subsubsection{Lactobacillosis}

This entity is characterized by the overgrowth of lactobacilli, without cellular lysis (Fig. 24.18). When symptomatic, it is very similar to CV. There is no epidemiological data in the literature concerning lactobacillosis.

The diagnosis is established by a normal or reduced $\mathrm{pH}$, cultures negative for Candida, and, most important, by an increased number of lactobacilli in microscopy, without other types of

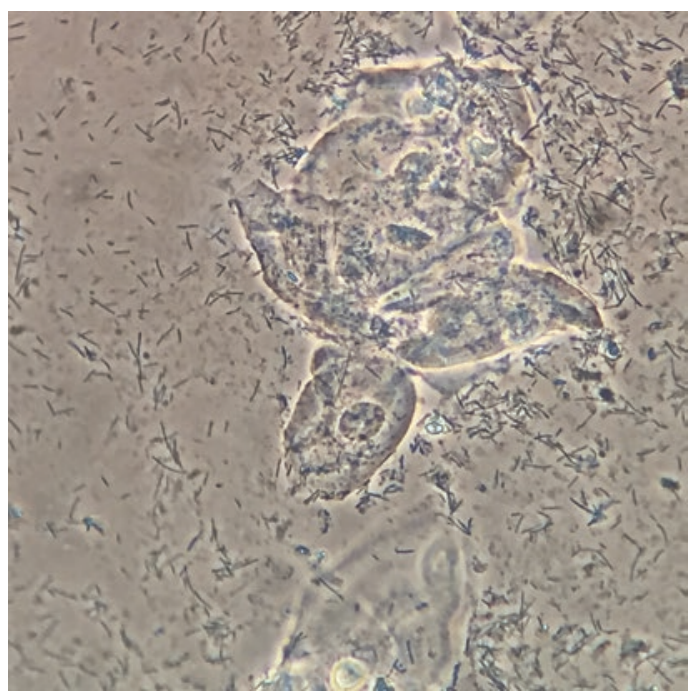

Fig. 24.18 Lactobacillosis (phase contrast 400×) 
bacteria, cytolysis, inflammation, clue cells, or T. vaginalis (Table 24.12).

It is believed that it is self-limited, thus expectant management is an option. In cases in which treatment is needed, it is similar to that of $\mathrm{CV}$ (Table 24.11).

\subsection{3 "Leptothrix"}

Leptothrix is a controversial entity; even those who acknowledge its existence do not agree in how it should be designated (alternative names include "fusiform lactobacilli") [160]. It is characterized

Table 24.11 Treatment of CV, lactobacillosis and leptothrix

\begin{tabular}{l|l|l}
\hline $\begin{array}{l}\text { Cytolytic vaginosis } \\
\text { Lactobacillosis }\end{array}$ & Sodium bicarbonate & $\begin{array}{l}30-40 \mathrm{mg} \text { should be diluted in 1 L of warm water and } \\
\text { vaginal irrigations performed daily for 2 weeks } \\
\text { Maintenance, if needed, should be kept as the } \\
\text { minimum required to control the symptoms }\end{array}$ \\
\hline Leptothrix & Amoxicillin + clavulanate 500/125 & $\begin{array}{l}\text { First choice } \\
3 \text { id for 7 days }\end{array}$ \\
\cline { 2 - 3 } & Doxycycline $100 \mathrm{mg}[158]$ & $\begin{array}{l}\text { If allergic to penicillin } \\
\text { 2 id for 10 days }\end{array}$ \\
\cline { 2 - 3 } & Nifuratel $200 \mathrm{mg}$ & $\begin{array}{l}\text { Alternative needing further tests } \\
3 \text { id for 7 days }\end{array}$ \\
\hline
\end{tabular}

Table 24.12 Wet mount characterization and differential diagnosis of vulvovaginitis

\begin{tabular}{|c|c|c|c|c|c|}
\hline & $\begin{array}{l}\text { Presence of } \\
\text { parabasal/ } \\
\text { basal cells }\end{array}$ & Lactobacilli & Inflammation & Other & Notes \\
\hline $\begin{array}{l}\text { Candidiasis or } \\
\text { candidosis }\end{array}$ & - & Normal & Can be present & $\begin{array}{l}\text { Hyphae, } \\
\text { pseudohyphae, } \\
\text { spores }\end{array}$ & $\begin{array}{l}\text { Inflammation, if present, } \\
\text { usually without toxic } \\
\text { leucocytes } \\
\text { C. glabrata presents only as } \\
\text { blastospores } \\
\text { Presence of pseudohyphae is } \\
\text { highly suggestive of infection } \\
\text { rather than colonization } \\
\text { Blastospores of } C \text {. } \\
\text { parapsilosis and } S \text {. cerevisiae } \\
\text { are larger than those of } C \text {. } \\
\text { glabrata }\end{array}$ \\
\hline Trichomoniasis & $-/+$ & $\begin{array}{l}\text { Frequently } \\
\text { decreased }\end{array}$ & $\begin{array}{l}+ \\
\text { (frequently } \\
\text { exuberant and } \\
\text { with toxic } \\
\text { leukocytes) }\end{array}$ & $\begin{array}{l}\text { Motile } \\
\text { protozoarians } \\
\text { can be seen } \\
(10-20 \text { by } \\
2-14 \mu \mathrm{m})\end{array}$ & $\begin{array}{l}\text { Frequently associated with } \\
\text { BV. If slide kept warm and } \\
\text { microscopy performed } \\
\text { immediately after collection, } \\
\text { the likelihood of seeing } \\
\text { motile TV is higher }\end{array}$ \\
\hline $\begin{array}{l}\text { Bacterial } \\
\text { vaginosis }\end{array}$ & - & $\begin{array}{l}\text { Decreased/ } \\
\text { absent }\end{array}$ & - & Clue cells & $\begin{array}{l}\text { If inflammation is present, } \\
\text { exclude other causes for it }\end{array}$ \\
\hline $\begin{array}{l}\text { Aerobic } \\
\text { vaginitis }\end{array}$ & + & $\begin{array}{l}\text { Decreased/ } \\
\text { absent }\end{array}$ & + & $\begin{array}{l}\text { Toxic leucocytes } \\
\text { can be present }\end{array}$ & - \\
\hline $\begin{array}{l}\text { Cytolytic } \\
\text { vaginosis }\end{array}$ & - & Increased & - & $\begin{array}{l}\text { Bare nuclei and } \\
\text { cellular debris }\end{array}$ & - \\
\hline Lactobacillosis & - & $\begin{array}{l}\text { Increased } \\
\text { and long }\end{array}$ & - & - & - \\
\hline Leptothrix & - & Long & - & - & $\begin{array}{l}\text { Lactobacilli longer than in } \\
\text { lactobacillosis } \\
\text { Can coexist with normal } \\
\text { lactobacilli, BV, or even TV }\end{array}$ \\
\hline
\end{tabular}




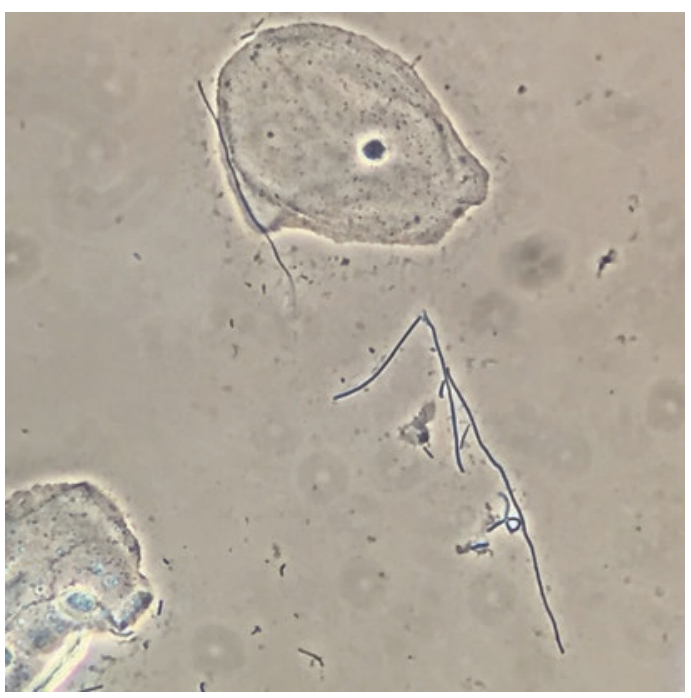

Fig. 24.19 Leptothrix (phase contrast 400x)

by the presence of long, filamentous lactobacilli, sometimes with segmentation and/or sporulation (Fig. 24.19). Its size can be $8-15$ times that of a normal lactobacillus [161]. It can totally dominate the flora or be associated with normal lactobacilli, lactobacillosis [158], or even BV type flora and T. vaginalis. In a Swedish study, its prevalence in a cohort of women without BV was $8 \%$. These authors identified these bacteria as L. gasseri [160].

There is some speculation that these lactobacilli may be the consequence of the previous use of antibiotics or antifungals.

Horowitz et al. described women with cyclical symptoms of vulvar discomfort and vaginal discharge during the luteal phase, associated with the presence of long and serpiginous lactobacilli.

The diagnosis is easily made by microscopy, by the presence of the typical long bacteria, that should not be confused with Candida or Actinomyces (Table 24.12).

Treatment with oral antibiotics has proven to be highly effective, both in the control and symptoms and in the elimination of the bacteria [158]. The first choice is amoxicillin + clavulanate; in women allergic to penicillin, doxycycline is an alternative [158]. Nifuratel has also been tested, but with much higher rates of relapse [162] (Table 24.11).

In contrast to other authors' experience, we have seen recurrences, even after successful treatment.

\subsection{Other Conditions to Consider in the Differential Diagnosis of Vaginal Discharge}

Several other conditions can present in similar ways to vulvovaginitis and must be considered in the differential diagnosis.

\section{Vaginal Atrophy: Breaking the Myth \\ "Vaginal atrophy" and "atrophic vaginitis" may be associated with vaginal discharge. These terms have recently been renamed: "genitourinary syndrome of menopause". However, no minimum number of criteria was defined, the list of signs and symptoms is not specific, and some of the mainstays for its creation are highly debatable.}

Postmenopausal vaginal atrophy can present in two ways: (1) without discharge (on microscopy there is paucity of epithelial cells and no inflammation) and (2) with purulent discharge (abundance of deep layer cells and inflammation-“atrophic vaginitis"). In 2014, the North American Menopause Society and the International Society for the Study of Women's Sexual Health proposed that "vaginal atrophy" and "atrophic vaginitis" should be replaced by "genitourinary syndrome of menopause". However, we disagree with this concept, as it cannot be considered a syndrome (which, by definition, is a particular abnormality or condition), no minimum number of criteria was defined, the list of signs and symptoms is not specific, and some of the mainstays for its creation are highly debatable (like "atrophy" having a negative connotation or "vagina" not being a well accepted term) [163].

Vaginal involvement of erosive lichen planus can manifest itself also with by a purulent discharge, sometimes with more or less extensive formation of synechia.

Other causes to be considered include allergic and contact vaginitis, as well as cervical ectopy [53] (Table 24.13). 
Table 24.13 Clinical characteristics and potential risks of different causes of vulvovaginitis

\begin{tabular}{|c|c|c|c|c|c|c|}
\hline & $\mathrm{pH}$ & Whiff test & $\begin{array}{l}\text { Variation of symptoms } \\
\text { during ovarian cycle }\end{array}$ & Symptoms & Signs & Risks \\
\hline Candidiasis & $\begin{array}{l}\text { Normal } \\
\text { (but can occur at any } \\
\text { pH; most likely to } \\
\text { be symptomatic at } \\
\text { low pH) }\end{array}$ & - & $\begin{array}{l}\text { Worsening during } \\
\text { the luteal phase and } \\
\text { improving with } \\
\text { menses }\end{array}$ & $\begin{array}{l}\text { Pruritus, terminal/ } \\
\text { post-micturition } \\
\text { dysuria, dyspareunia. } \\
\text { If burning is the main } \\
\text { symptom consider } C \text {. } \\
\text { non-albicans or } \\
\text { alternative diagnosis }\end{array}$ & $\begin{array}{l}\text { Erythema and } \\
\text { enantema, fissures, } \\
\text { oedema, white, curdy } \\
\text { discharge, without } \\
\text { foul smell }\end{array}$ & $\begin{array}{l}\text { - Limited data relating it } \\
\text { to bad obstetrical } \\
\text { outcomes } \\
\text { - Increased risk of HIV }\end{array}$ \\
\hline Trichomoniasis & Increased $(\geq 5)$ & + (frequently) & $\begin{array}{l}\text { Worsening of } \\
\text { symptoms during } \\
\text { menses }\end{array}$ & $\begin{array}{l}\text { Can be asymptomatic } \\
\text { Dysuria, burning, } \\
\text { itching, irritation, } \\
\text { discharge }\end{array}$ & $\begin{array}{l}\text { Erythema, enantema, } \\
\text { erosions, fissures, } \\
\text { strawberry cervix, } \\
\text { yellow or green } \\
\text { purulent discharge } \\
\text { (sometimes with } \\
\text { bubbles), discharge } \\
\text { can have a rotten } \\
\text { smell }\end{array}$ & $\begin{array}{l}\text { - Adverse obstetrical } \\
\text { outcomes } \\
\text { - STIs (HIV) }\end{array}$ \\
\hline Bacterial vaginosis & Increased $(>4.5)$ & + & $\begin{array}{l}\text { Worsening of } \\
\text { symptoms during } \\
\text { menses }\end{array}$ & $\begin{array}{l}\text { Fishy smell, mild } \\
\text { burning }\end{array}$ & $\begin{array}{l}\text { Grey or yellow, thin, } \\
\text { adherent discharge }\end{array}$ & $\begin{array}{l}\text { - Adverse obstetrical and } \\
\text { neonatal outcomes } \\
\text { - STIs } \\
\text { - Cervical dysplasia/ } \\
\text { cancer }\end{array}$ \\
\hline Aerobic vaginitis & $\begin{array}{l}\text { Increased (usually } \\
\text { more than in BV: } \\
>5 \text { ) }\end{array}$ & - & $\begin{array}{l}\text { Worsening of } \\
\text { symptoms during } \\
\text { menses? }\end{array}$ & $\begin{array}{l}\text { Rotten wood smell } \\
\text { discharge; burning, } \\
\text { stinging, dyspareunia }\end{array}$ & $\begin{array}{l}\text { Yellow or green } \\
\text { purulent discharge; } \\
\text { erosions, enantema }\end{array}$ & $\begin{array}{l}\text { - Adverse obstetrical and } \\
\text { neonatal outcomes } \\
\text { - STIs } \\
\text { - Abnormal pap tests }\end{array}$ \\
\hline Cytolytic vaginosis & Lower than normal & - & $\begin{array}{l}\text { Worsening during } \\
\text { the luteal phase and } \\
\text { marked improvement } \\
\text { with menses }\end{array}$ & $\begin{array}{l}\text { Burning, abundant } \\
\text { discharge }\end{array}$ & $\begin{array}{l}\text { White, curdy, } \\
\text { abundant discharge }\end{array}$ & • Vulvodynia (?) \\
\hline Lactobacillosis & Lower than normal & - & $\begin{array}{l}\text { Worsening during } \\
\text { the luteal phase and } \\
\text { marked improvement } \\
\text { with menses }\end{array}$ & Burning & $\begin{array}{l}\text { Normal/white } \\
\text { discharge }\end{array}$ & - Not reported \\
\hline Leptothrix & Normal/low (?) & - & $?$ & $\begin{array}{l}\text { Asymptomatic most of } \\
\text { time times } \\
\text { Burning }\end{array}$ & Normal & - Not reported \\
\hline
\end{tabular}




\section{References}

1. Sobel JD, et al. Vulvovaginal candidiasis: epidemiologic, diagnostic, and therapeutic considerations. Am J Obstet Gynecol. 1998;178:203-11.

2. Mendling W, et al. Guideline: vulvovaginal candidosis (AWMF 015/072), S2k (excluding chronic mucocutaneous candidosis). Mycoses. 2015;58:1-15.

3. Nedovic B, et al. Mannose-binding lectin codon 54 gene polymorphism and vulvovaginal candidiasis: a systematic review and meta-analysis. Biomed Res Int. 2014;2014:1-7.

4. Donders GGG, Bellen G, Mendling W. Management of recurrent vulvo-vaginal candidosis as a chronic illness. Gynecol Obstet Investig. 2010;70:306-21.

5. Matsubara VH, Wang Y, Bandara HMHN, Mayer MPA, Samaranayake LP. Probiotic lactobacilli inhibit early stages of Candida albicans biofilm development by reducing their growth, cell adhesion, and filamentation. Appl Microbiol Biotechnol. 2016;100:6415-26.

6. Sobel JD. Vulvovaginal candidosis. Lancet. 2007;369:1961-71.

7. Sobel JD, Subramanian C, Foxman B, Fairfax M, Gygax SE. Mixed vaginitis-more than coinfection and with therapeutic implications. Curr Infect Dis Rep. 2013;15:104-8.

8. Lindner JG, Plantema FH, Hoogkamp-Korstanje JA. Quantitative studies of the vaginal flora of healthy women and of obstetric and gynaecological patients. J Med Microbiol. 1978;11:233-41.

9. Beigi RH, Meyn LA, Moore DM, Krohn MA, Hillier SL. Vaginal yeast colonization in nonpregnant women: a longitudinal study. Obstet Gynecol. 2004;104:926-30.

10. Workowski KA, Bolan GA, Centers for Disease Control and Prevention. Sexually transmitted diseases treatment guidelines, 2015. MMWR Morb Mortal Wkly Rep. 2015;64:1-137.

11. Ventolini G. Progresses in vaginal microflora physiology and implications for bacterial vaginosis and candidiasis. Women's Health (Lond Engl). 2016;12:283-91.

12. Dennerstein GJ, Ellis DH. Oestrogen, glycogen and vaginal candidiasis. Aust N Z J Obstet Gynaecol. 2001;41:326-8.

13. Alves CT, et al. Effect of progesterone on Candida albicans vaginal pathogenicity. Int J Med Microbiol. 2014;304:1011-7.

14. Donders G, et al. Influence of contraceptive choice on vaginal bacterial and fungal microflora. Eur J Clin Microbiol Infect Dis. 2017;36:43-8.

15. Erol O, Simavlı S, Derbent AU, Ayrim A, Kafalı H. The impact of copper-containing and levonorgestrel-releasing intrauterine contraceptives on cervicovaginal cytology and microbiological flora: a prospective study. Eur J Contracept Reprod Health Care. 2014;19:187-93.
16. Lete I, Cuesta MC, Marín JM, Guerra S. Vaginal health in contraceptive vaginal ring users - a review. Eur J Contracept Reprod Health Care. 2013;18:234-41.

17. Farage M, Bramante M, Otaka Y, Sobel J. Do panty liners promote vulvovaginal candidiasis or urinary tract infections? Eur J Obstet Gynecol Reprod Biol. 2007;132:8-19.

18. Anderson MR, Klink K, Cohrssen A. Evaluation of vaginal complaints. JAMA. 2004;291:1368-79.

19. Holzer I, Farr A, Kiss H, Hagmann M, Petricevic L. The colonization with Candida species is more harmful in the second trimester of pregnancy. Arch Gynecol Obstet. 2017;295:891-5.

20. Garcia-Flores J, et al. Candida chorioamnionitis: report of two cases and review of literature. J Obstet Gynaecol. 2016;36:843-4.

21. Hester RA, Kennedy SB. Candida infection as a risk factor for HIV transmission. J Womens Health. 2003;12:487-94.

22. Foster DC, et al. Site-specific mesenchymal control of inflammatory pain to yeast challenge in vulvodynia-afflicted and pain-free women. Pain. 2015;156:386-96.

23. Ferris DG, Dekle C, Litaker MS. Women's use of over-the-counter antifungal medications for gynecologic symptoms. J Fam Pract. 1996;42:595-600.

24. Emmerson J, et al. Sampling for vaginal candidosis: how good is it? Int J STD AIDS. 1994;5:356-8.

25. Cartwright $\mathrm{CP}$, et al. Comparison of nucleic acid amplification assays with BD affirm VPIII for diagnosis of vaginitis in symptomatic women. J Clin Microbiol. 2013;51(11):3694-9. https://doi. org/10.1128/JCM.01537-13.

26. Brown HL, Fuller DD, Jasper LT, Davis TE, Wright JD. Clinical evaluation of affirm VPIII in the detection and identification of Trichomonas vaginalis, Gardnerella vaginalis, and candida species in vaginitis/vaginosis. Infect Dis Obstet Gynecol. 2004; 12:17-21.

27. Weissenbacher $\mathrm{T}$, et al. Relationship between clinical diagnosis of recurrent vulvovaginal candidiasis and detection of candida species by culture and polymerase chain reaction. Arch Gynecol Obstet. 2009;279:125-9.

28. Donders G, et al. Individualized decreasing-dose maintenance fluconazole regimen for recurrent vulvovaginal candidiasis ( $\mathrm{ReCiDiF}$ trial). Am J Obstet Gynecol. 2008;199:613.e1-9.

29. Donders GGG, et al. Role of molecular biology in diagnosis and characterization of Vulvo-vaginitis in clinical practice. Gynecol Obstet Investig. 2017;82:607-16.

30. Gaydos CA, et al. Clinical validation of a test for the diagnosis of vaginitis. Obstet Gynecol. 2017;130:181-9.

31. Martin Lopez JE. Candidiasis (vulvovaginal). BMJ Clin Evid. 2015. pii: 0815. https://www.ncbi.nlm. nih.gov/pubmed/25775428. 
32. Pitsouni E, Iavazzo C, Falagas ME. Itraconazole vs fluconazole for the treatment of uncomplicated acute vaginal and vulvovaginal candidiasis in nonpregnant women: a metaanalysis of randomized controlled trials. Am J Obstet Gynecol. 2008;198(2):153-60. https://doi.org/10.1016/j.ajog.2007.10.786.

33. Consolaro MEL, Albertoni TA, Svidzinski AE, Peralta RM, Svidzinski TIE. Vulvovaginal candidiasis is associated with the production of germ tubes by Candida albicans. Mycopathologia. 2005;159:501-7.

34. Mahmoudabadi AZ, Najafyan M, Moghimipour E, Alwanian M, Seifi Z. Lamisil versus clotrimazole in the treatment of vulvovaginal candidiasis. Iran J Microbiol. 2013;5:86-90.

35. Ferahbas A, et al. Terbinafine versus Itraconazole and fluconazole in the treatment of vulvovaginal candidiasis. Am J Ther. 2006;13(4):332-6. https:// doi.org/10.1097/00045391-200607000-00010.

36. Sobel JD, et al. Maintenance fluconazole therapy for recurrent vulvovaginal candidiasis. $\mathrm{N}$ Engl $\mathrm{J}$ Med. 2004;351:876-83.

37. Dennerstein GJ. Depo-Provera in the treatment of recurrent vulvovaginal candidiasis. J Reprod Med. 1986;31:801-3.

38. Vieira-Baptista P, Donders G. Is it possible to prevent recurrent vulvovaginitis? The role of lactobacillus plantarum I1001 (CECT7504). Eur J Clin Microbiol Infect Dis. 2017;36(3):593-4. https://doi. org/10.1007/s10096-016-2861-z.

39. Papaemmanouil V, et al. Prevalence and susceptibility of Saccharomyces cerevisiae causing vaginitis in Greek women. Anaerobe. 2011;17:298-9.

40. Nyirjesy P, et al. Saccharomyces cerevisiae vaginitis: transmission from yeast used in baking. Obstet Gynecol. 1995;86:326-9.

41. Kissinger P. Epidemiology and treatment of trichomoniasis. Curr Infect Dis Rep. 2015;17:31.

42. Petrin D, Delgaty K, Bhatt R, Garber G. Clinical and microbiological aspects of Trichomonas vaginalis. Clin Microbiol Rev. 1998;11:300-17.

43. Fichorova R, Fraga J, Rappelli P, Fiori PL. Trichomonas vaginalis infection in symbiosis with Trichomonasvirus and mycoplasma. Res Microbiol. 2017;168(9-10):882-91. https://doi.org/10.1016/j. resmic.2017.03.005.

44. Menezes CB, Amanda Piccoli Frasson AP, Tasca T. Trichomoniasis - are we giving the deserved attention to the most common non-viral sexually transmitted disease worldwide? Microb Cell. 2016;3:404-18.

45. Rowley J, Toskin I, Ndowa F, World Health Organization. Reproductive health and research. Global incidence and prevalence of selected curable sexually transmitted infections, 2008. Geneva: World Health Organization; 2012.

46. Krieger JN. Trichomoniasis in men: old issues and new data. Sex Transm Dis. 1995;22:83-96.

47. Byun JM, et al. Experience of successful treatment of patients with metronidazole-resistant Trichomonas vaginalis with zinc sulfate: a case series. Taiwan $\mathrm{J}$ Obstet Gynecol. 2015;54:617-20.

48. Sena AC, et al. Trichomonas vaginalis infection in male sexual partners: implications for diagnosis, treatment, and prevention. Clin Infect Dis. 2007;44:13-22.

49. Schwebke JR, Burgess D. Trichomoniasis. Clin Microbiol Rev. 2004;17:794-803.

50. Donders GGG, Depuydt C. Increased prevalence of Trichomonas vaginalis in mid-aged women is linked to sexual activity and not to hormonal changes. J Low Genit Tract Dis. 2013;17:e31-2.

51. Sutton M, et al. The prevalence of Trichomonas vaginalis infection among reproductive-age women in the United States, 2001-2004. Clin Infect Dis. 2007;45:1319-26.

52. Freeman $\mathrm{AH}$, et al. Prevalence and correlates of Trichomonas vaginalis among incarcerated persons assessed using a highly sensitive molecular assay. Sex Transm Dis. 2010;37:165-8.

53. Sherrard J, Donders G, White D. European (IUSTI/ WHO) guideline on the management of vaginal discharge, 2011. Int J STD AIDS. 2011;22:421-9.

54. Lima-Silva J, Vieira-Baptista P, Cavaco-Gomes J, Maia T, Beires J. Emphysematous vaginitis. J Low Genit Tract Dis. 2015;19:e43-4.

55. Silver BJ, Guy RJ, Kaldor JM, Jamil MS, Rumbold AR. Trichomonas vaginalis as a cause of perinatal morbidity: a systematic review and meta-analysis. Sex Transm Dis. 2014;41:369-76.

56. Cotch MF, et al. Trichomonas vaginalis associated with low birth weight and preterm delivery. The vaginal Infections and Prematurity Study Group. Sex Transm Dis. 1997;24:353-60.

57. Donders G, Bellen G, Rezeberga D. Aerobic vaginitis in pregnancy. BJOG. 2011;118:1163-70.

58. Fastring DR, et al. Co-occurrence of Trichomonas vaginalis and bacterial Vaginosis and vaginal shedding of HIV-1 RNA. Sex Transm Dis. 2014;41:173-9.

59. Mavedzenge SN, et al. Epidemiological synergy of Trichomonas vaginalis and HIV in Zimbabwean and south African women. Sex Transm Dis. 2010;37:460-6.

60. Donders GGG, Depuydt CE, Bogers J-P, Vereecken AJ. Association of Trichomonas vaginalis and cytological abnormalities of the cervix in low risk women. PLoS One. 2013;8:e86266.

61. Hamilton $\mathrm{H}$, et al. Trichomonas vaginalis brain abscess in a neonate. Clin Infect Dis. 2017;66(4):6047. https://doi.org/10.1093/cid/cix908.

62. Jones HE, Lippman SA, Caiaffa-Filho HH, Young T, van de Wijgert JHHM. Performance of a rapid self-test for detection of Trichomonas vaginalis in South Africa and Brazil. J Clin Microbiol. 2013;51:1037-9.

63. Van Der Pol B. Clinical and laboratory testing for Trichomonas vaginalis infection. J Clin Microbiol. 2016;54:7-12.

64. Wiese W, Patel SR, Patel SC, Ohl CA, Estrada CA. A meta-analysis of the Papanicolaou smear and 
wet mount for the diagnosis of vaginal trichomoniasis. Am J Med. 2000;108:301-8.

65. Nathan B, et al. Microscopy outperformed in a comparison of five methods for detecting Trichomonas vaginalis in symptomatic women. Int J STD AIDS. 2015;26:251-6.

66. Nye MB, Schwebke JR, Body BA. Comparison of APTIMA Trichomonas vaginalis transcriptionmediated amplification to wet mount microscopy, culture, and polymerase chain reaction for diagnosis of trichomoniasis in men and women. Am J Obstet Gynecol. 2009;200:188.e1-7.

67. Gaydos CA, et al. Rapid diagnosis of Trichomonas vaginalis by testing vaginal swabs in an isothermal helicase-dependent AmpliVue assay. Sex Transm Dis. 2016;43:369-73.

68. Perl G. Errors in the diagnosis of trichomonas vaginalis infections as observed among 1199 patients. Obstet Gynecol. 1972;39:7-9.

69. Badman SG, et al. A preliminary evaluation of a new GeneXpert (Gx) molecular point-of-care test for the detection of Trichomonas vaginalis. Sex Transm Infect. 2016;92:350-2.

70. Visapää J-P, Tillonen JS, Kaihovaara PS, Salaspuro MP. Lack of disulfiram-like reaction with metronidazole and ethanol. Ann Pharmacother. 2002;36:971-4.

71. Sobel R, Sobel JD. Metronidazole for the treatment of vaginal infections. Expert Opin Pharmacother. 2015;16:1109-15.

72. Schwebke JR, Lensing SY, Sobel J. Intravaginal metronidazole/miconazole for the treatment of vaginal trichomoniasis. Sex Transm Dis. 2013;40:710-4.

73. Klebanoff MA, et al. Failure of metronidazole to prevent preterm delivery among pregnant women with asymptomatic Trichomonas vaginalis infection. N Engl J Med. 2001;345:487-93.

74. Gülmezoglu AM, Azhar M. Interventions for trichomoniasis in pregnancy. Cochrane Database Syst Rev. 2011;11:CD000220. https://doi. org/10.1002/14651858.CD000220.pub2.

75. Crucitti T. Eve's garden: myths, legends and secrets unmasked. Res Microbiol. 2017;168(9-10):773-81. https://doi.org/10.1016/j.resmic.2017.07.004.

76. Donders G, Vieira-Baptista P. Bacterial vaginosis and inflammatory response showed association with severity of cervical neoplasia in HPV-positive women. Diagn Cytopathol. 2016;45(5):472-3.

77. Donders GGG, et al. Definition of a type of abnormal vaginal flora that is distinct from bacterial vaginosis: aerobic vaginitis. BJOG. 2002;109:34-43.

78. Vieira-Baptista P, et al. Bacterial vaginosis, aerobic vaginitis, vaginal inflammation and major pap smear abnormalities. Eur J Clin Microbiol Infect Dis. 2016;35:1-8. https://doi.org/10.1007/ s10096-016-2584-1.

79. Ravel J, et al. Vaginal microbiome of reproductiveage women. Proc Natl Acad Sci U S A. 2011;108(Suppl 1):4680-7. https://doi.org/10.1073/ pnas. 1002611107.
80. Miller EA, Beasley DE, Dunn RR, Archie EA. Lactobacilli dominance and vaginal $\mathrm{pH}$ : why is the human vaginal microbiome unique? Front Microbiol. 2016;7:1936.

81. Blackwell AL. Vaginal bacterial phaginosis? Sex Transm Infect. 1999;75:352-3.

82. Marrazzo JM, Thomas KK, Fiedler TL, Ringwood K, Fredricks DN. Risks for acquisition of bacterial vaginosis among women who report sex with women: a cohort study. PLoS One. 2010;5:e11139.

83. Harada K, et al. Vaginal infection with Ureaplasma urealyticum accounts for preterm delivery via induction of inflammatory responses. Microbiol Immunol. 2008;52:297-304.

84. Nasioudis D, Linhares I, Ledger W, Witkin S. Bacterial vaginosis: a critical analysis of current knowledge. BJOG An Int J Obstet Gynaecol. 2017;124:61-9.

85. Hay P. Bacterial vaginosis. F1000Res. 2017;6:1761.

86. Allsworth JE, Peipert JF. Prevalence of bacterial vaginosis. Obstet Gynecol. 2007;109:114-20.

87. Vieira-Baptista $P$, et al. Genital tract infections in an isolated community: 100 women of the Príncipe Island. Infect Dis Obstet Gynecol. 2017;2017:3058569.

88. Yen S, et al. Bacterial vaginosis in sexually experienced and non-sexually experienced young women entering the military. Obstet Gynecol. 2003;102:927-33.

89. Marrazzo JM, Thomas KK, Agnew K, Ringwood $\mathrm{K}$. Prevalence and risks for bacterial vaginosis in women who have sex with women. Sex Transm Dis. 2010;37:335-9.

90. Gottschick C, et al. The urinary microbiota of men and women and its changes in women during bacterial vaginosis and antibiotic treatment. Microbiome. 2017;5:99.

91. Gray RH, et al. The effects of male circumcision on female partners' genital tract symptoms and vaginal infections in a randomized trial in Rakai, Uganda. Am J Obstet Gynecol. 2009;200(42):e1-7.

92. Bilardi JE, et al. Women view key sexual behaviours as the trigger for the onset and recurrence of bacterial vaginosis. PLoS One. 2017;12:e0173637.

93. Brotman RM, et al. Association between cigarette smoking and the vaginal microbiota: a pilot study. BMC Infect Dis. 2014;14:471.

94. Petrova MI, Reid G, Vaneechoutte M, Lebeer S. Lactobacillus iners: friend or foe? Trends Microbiol. 2017;25:182-91.

95. Marrazzo JM, Antonio M, Agnew K, Hillier SL. Distribution of genital lactobacillus strains shared by female sex partners. J Infect Dis. 2009;199:680-3.

96. Taylor-Robinson D, McCaffrey M, Pitkin J, Lamont RF. Bacterial vaginosis in climacteric and menopausal women. Int J STD AIDS. 2002;13:449-52.

97. Eschenbach DA, Gravett MG, Chen KC, Hoyme UB, Holmes KK. Bacterial vaginosis during pregnancy. An association with prematurity and post- 
partum complications. Scand J Urol Nephrol Suppl. 1984;86:213-22.

98. Unemo M, et al. Sexually transmitted infections: challenges ahead. Lancet Infect Dis. 2017;17:e235-79.

99. Donders GGG, Ruban K, Bellen G, Petricevic L. Mycoplasma/Ureaplasma infection in pregnancy: to screen or not to screen. J Perinat Med. 2017;45:505-15.

100. Cohen CR, et al. Bacterial vaginosis associated with increased risk of female-to-male HIV-1 transmission: a prospective cohort analysis among African couples. PLoS Med. 2012;9:e1001251.

101. Babu G, Singaravelu BG, Srikumar R, Reddy SV, Kokan A. Comparative study on the vaginal flora and incidence of asymptomatic vaginosis among healthy women and in women with infertility problems of reproductive age. J Clin Diagn Res. 2017;11:DC18-22.

102. Amsel R, et al. Nonspecific vaginitis. Diagnostic criteria and microbial and epidemiologic associations. Am J Med. 1983;74(1):14-22. https://doi. org/10.1016/0002-9343(83)91137-3.

103. Mittal V, Jain A, Pradeep Y, Pradeep Y. Development of modified diagnostic criteria for bacterial vaginosis at peripheral health centres in developing countries. J Infect Dev Countries. 2012;6:373-7.

104. Hay P, Tummon A, Ogunfile M, Adebiyi A, Adefowora A. Evaluation of a novel diagnostic test for bacterial vaginosis: 'the electronic nose'. Int J STD AIDS. 2003;14:114-8.

105. Huppert JS, et al. Accuracy and trust of selftesting for bacterial vaginosis. J Adolesc Health. 2012;51:400-5.

106. Geva A, Bornstein J, Dan M, Shoham HK, Sobel JD. The VI-SENSE-vaginal discharge self-test to facilitate management of vaginal symptoms. Am J Obstet Gynecol. 2006;195:1351-6.

107. Nugent R, Krohn M, Hillier S. Reliability of diagnosing bacterial vaginosis is improved by a standardized method of gram stain interpretation. J Clin Microbiol. 1991;29:297-301.

108. Donders GGG. Definition and classification of abnormal vaginal flora. Best Pract Res Clin Obstet Gynaecol. 2007;21:355-73.

109. Ison CA, Hay PE. Validation of a simplified grading of gram stained vaginal smears for use in genitourinary medicine clinics. Sex Transm Infect. 2002;78:413-5.

110. Stockdale CK. A positive culture result for gardnerella is not diagnostic of bacterial vaginosis. J Low Genit Tract Dis. 2016;20:281-2.

111. Madhivanan P, et al. Performance of BVBlue rapid test in detecting bacterial vaginosis among women in Mysore, India. Infect Dis Obstet Gynecol. 2014;2014:908313.

112. Calderón E, Rivera R. Evaluation of a fast test to identify the presence of proline aminopeptidase in women with bacterial Vaginosis. Infect Dis Obstet Gynecol. 1997;231:226-31.
113. Rumyantseva $\mathrm{T}$ a, Bellen G, Savochkina YA, Guschin a E, Donders GGG. Diagnosis of aerobic vaginitis by quantitative real-time PCR. Arch Gynecol Obstet. 2016;294(1):109-14. https://doi. org/10.1007/s00404-015-4007-4.

114. Oduyebo OO, Anorlu RI, Ogunsola FT. In: Oduyebo $\mathrm{OO}$, editor. Cochrane database of systematic reviews. Hoboken: Wiley; 2009. p. CD006055. https://doi. org/10.1002/14651858.CD006055.pub2.

115. Donders GG, Zodzika J, Rezeberga D. Treatment of bacterial vaginosis: what we have and what we miss. Expert Opin Pharmacother. 2014;15:645-57.

116. Mendling W, Weissenbacher ER, Gerber S, Prasauskas V, Grob P. Use of locally delivered dequalinium chloride in the treatment of vaginal infections: a review. Arch Gynecol Obstet. 2015;293(3):469-84. s00404-015-3914-8.

117. Schuyler JA, et al. Identification of intrinsically metronidazole-resistant clades of Gardnerella vaginalis. Diagn Microbiol Infect Dis. 2016;84:1-3.

118. Donders G, et al. Improvement of abnormal vaginal flora in Ugandan women by self-testing and short use of intravaginal antimicrobials. Eur J Clin Microbiol Infect Dis. 2016;36(4):731-8. https://doi. org/10.1007/s10096-016-2856-9.

119. Chaithongwongwatthana S, Limpongsanurak S, Sitthi-Amorn C. Single hydrogen peroxide vaginal douching versus single-dose oral metronidazole for the treatment of bacterial vaginosis: a randomized controlled trial. J Med Assoc Thail. 2003;86(Suppl 2):S379-84.

120. Krasnopolsky VN, et al. Efficacy of vitamin C vaginal tablets as prophylaxis for recurrent bacterial vaginosis: a randomised, double-blind, placebo-controlled clinical trial. J Clin Med Res. 2013;5:309-15.

121. Tan H, Fu Y, Yang C, Ma J. Effects of metronidazole combined probiotics over metronidazole alone for the treatment of bacterial vaginosis: a meta-analysis of randomized clinical trials. Arch Gynecol Obstet. 2017;295:1331-9.

122. Ugwumadu A, Manyonda I, Reid F, Hay P. Effect of early oral clindamycin on late miscarriage and preterm delivery in asymptomatic women with abnormal vaginal flora and bacterial vaginosis: a randomised controlled trial. Lancet. 2003;361:983-8.

123. Larsson P-G, et al. Late miscarriage and preterm birth after treatment with clindamycin: a randomised consent design study according to Zelen. BJOG. 2006;113:629-37.

124. Lamont RF, Jones BM, Mandal D, Hay PE, Sheehan $M$. The efficacy of vaginal clindamycin for the treatment of abnormal genital tract flora in pregnancy. Infect Dis Obstet Gynecol. 2003;11:181-9.

125. Yudin MH, Money DM. No. 211-screening and management of bacterial vaginosis in pregnancy. J Obstet Gynaecol Canada. 2017;39:e184-91. 
126. Bradshaw CS, Sobel JD. Current treatment of bacterial vaginosis-limitations and need for innovation. J Infect Dis. 2016;214(Suppl 1): S14-20.

127. Verstraelen H, Swidsinski A. The biofilm in bacterial vaginosis: implications for epidemiology, diagnosis and treatment. Curr Opin Infect Dis. 2013;26:86-9.

128. Ferreira CST, et al. Treatment failure of bacterial vaginosis is not associated with higher loads of Atopobium vaginae and Gardnerella vaginalis. J Med Microbiol. 2017;66:1217-24.

129. Alves P, Castro J, Sousa C, Cereija TB, Cerca N. Gardnerella vaginalis outcompetes 29 other bacterial species isolated from patients with bacterial vaginosis, using in an in vitro biofilm formation model. J Infect Dis. 2014;210:593-6.

130. Marrazzo JM, Thomas KK, Fiedler TL, Ringwood K, Fredricks DN. Relationship of specific vaginal bacteria and bacterial vaginosis treatment failure in women who have sex with women. Ann Intern Med. 2008;149:20-8.

131. Bunge KE, Beigi RH, Meyn LA, Hillier SL. The efficacy of retreatment with the same medication for early treatment failure of bacterial vaginosis. Sex Transm Dis. 2009;36:711-3.

132. Sobel JD, et al. Suppressive antibacterial therapy with $0.75 \%$ metronidazole vaginal gel to prevent recurrent bacterial vaginosis. Am J Obstet Gynecol. 2006;194:1283-9.

133. McClelland RS, et al. Improvement of vaginal health for Kenyan women at risk for acquisition of human immunodeficiency virus type 1: results of a randomized trial. J Infect Dis. 2008;197:1361-8.

134. Mehta SD. Systematic review of randomized trials of treatment of male sexual partners for improved bacteria vaginosis outcomes in women. Sex Transm Dis. 2012;39:822-30.

135. Reichman O, Akins R, Sobel JD. Boric acid addition to suppressive antimicrobial therapy for recurrent bacterial vaginosis. Sex Transm Dis. 2009;36:732-4.

136. Heczko PB, et al. Supplementation of standard antibiotic therapy with oral probiotics for bacterial vaginosis and aerobic vaginitis: a randomised, double-blind, placebo-controlled trial. BMC Womens Health. 2015;15:115.

137. Xie HY, et al. Probiotics for vulvovaginal candidiasis in non-pregnant women. Cochrane Database Syst Rev. 2017;11:CD010496.

138. Verstraelen H, Verhelst R, Roelens K, Temmerman M. Antiseptics and disinfectants for the treatment of bacterial vaginosis: a systematic review. BMC Infect Dis. 2012;12:148.

139. Gardner HL. Desquamative inflammatory vaginitis: a newly defined entity. Am J Obstet Gynecol. 1968;102:1102-5.

140. Oates JK, Rowen D. Desquamative inflammatory vaginitis. A review. Genitourin Med. 1990;66:275-9.
141. Lima-silva J, Tavares S, Vieira-baptista P, Beires J. Desquamative inflammatory vaginitis. Acta Obstét Ginecol Port. 2016;10:317-25.

142. Donders GG, Bellen G, Grinceviciene S, Ruban K, Vieira-Baptista P. Aerobic vaginitis: no longer a stranger. Res Microbiol. 2017;168(9-10):845-58. https://doi.org/10.1016/j.resmic.2017.04.004.

143. Mitchell C, Fredricks D, Agnew K, Hitti J. Hydrogen peroxide-producing lactobacilli are associated with lower levels of vaginal interleukin-1 $\beta$, independent of bacterial vaginosis. Sex Transm Dis. 2015;42:358-63.

144. Marconi C, et al. Sialidase activity in aerobic vaginitis is equal to levels during bacterial vaginosis. Eur $\mathrm{J}$ Obstet Gynecol Reprod Biol. 2013;167:205-9.

145. Donders GGG, Vereecken A, Bosmans E, Spitz B. Vaginal cytokines in normal pregnancy. Am J Obstet Gynecol. 2003;189:1433-8.

146. Vieira-Baptista $P$, et al. Wet mount characterization of the vaginal flora of HIV women. In: 2nd ISIDOG meeting; 2017.

147. Geng N, et al. Analysis of the risk factors for aerobic vaginitis: a case-control study. Gynecol Obstet Investig. 2015. https://doi. org/10.1159/000431286.

148. Iwata T, et al. Cytokine profile in cervical mucosa of Japanese patients with cervical intraepithelial neoplasia. Int J Clin Oncol. 2015;20:126-33.

149. Donders GGG, et al. Increased vaginal $\mathrm{pH}$ in Ugandan women: what does it indicate? Eur J Clin Microbiol Infect Dis. 2016;35:1297-303.

150. Wang Z-L, et al. Diagnosis and microecological characteristics of aerobic vaginitis in outpatients based on preformed enzymes. Taiwan J Obstet Gynecol. 2016;55:40-4.

151. Witkin SS. Lactic acid alleviates stress: good for female genital tract homeostasis, bad for protection against malignancy. Cell Stress Chaperones. 2017;23(3):297-302.

https://doi.org/10.1007/ s12192-017-0852-3.

152. Soares R, Vieira-Baptista P, Tavares S. Cytolytic vaginosis: an underdiagnosed pathology that mimics vulvovaginal candidiasis. Acta Obstet Ginecol Port. 2017;11:106-12.

153. Witkin SS, et al. Influence of vaginal bacteria and D- and L-lactic acid isomers on vaginal extracellular matrix metalloproteinase inducer: implications for protection against upper genital tract infections. MBio. 2013;4:e00460-13.

154. Giraldo PC, et al. Influência da freqüência de coitos vaginais e da prática de duchas higiênicas sobre o equilíbrio da microbiota vaginal. Rev Bras Ginecol Obstet. 2005;27:257-62.

155. Vieira-Baptista P, Lima-Silva J, Beires J, Donders G. Cytolytic Vaginosis does not have an impact on human papilloma virus (HPV) infection and cervical dysplasia. Int J Low Genit Tract Dis. 2017;21:S27. 
156. Vieira-Baptista P, Lima-Silva J, Xavier J, Beires J, Donders G. Vaginal Flora influences the risk of Vulvodynia. J Low Genit Tract Dis. 2017;21:S26.

157. Ventolini G, Gygax SE, Adelson ME, Cool DR. Vulvodynia and fungal association: a preliminary report. Med Hypotheses. 2013;81:228-30.

158. Horowitz BJ, Mårdh PA, Nagy E, Rank EL. Vaginal lactobacillosis. Am J Obstet Gynecol. 1994;170:857-61.

159. Cibley LJ, Cibley LJ. Cytolytic vaginosis. Am J Obstet Gynecol. 1991;165:1245-9.

160. Platz-Christensen JJ, Påhlson C, Larsson PG. Long, uniform lactobacilli (Döderlein's Bacteria): a new risk factor for postoperative infection after first- trimester abortion. Infect Dis Obstet Gynecol. 1995;3:102-9.

161. Ventolini G. Vaginal leptothrix: from fungi to lactobacillosis. J Genit Syst Disord. 2015;4. https://www. scitechnol.com/vaginal-leptothrix-from-fungi-tolactobacillosis-oPa9.php?article_id=2738.

162. Cepický P, Malina J, Kuzelová M. Treatment of aerobic vaginitis and clinically uncertain causes of vulvovaginal discomfort. Ceska Gynekol. 2003;68:439-42.

163. Vieira-Baptista P, Marchitelli C, Haefner HK, Donders G, Pérez-López F. Deconstructing the genitourinary syndrome of menopause. Int Urogynecol J. 2017;28:675-9. 